\title{
Preference heterogeneity and optimal monetary policy
}

\section{Journal Article}

Author(s):

Uras, Burak R.; van Buggenum, Hugo

Publication date:

2022-01

Permanent link:

https://doi.org/10.3929/ethz-b-000522352

Rights / license:

Creative Commons Attribution 4.0 International

Originally published in:

Journal of Economic Dynamics \& Control 134, https://doi.org/10.1016/j.jedc.2021.104289 


\title{
Preference heterogeneity and optimal monetary policy
}

\author{
Burak R. Uras ${ }^{\mathrm{a}, *}$, Hugo van Buggenum ${ }^{\mathrm{b}}$ \\ a Department of Economics and CentER, Tilburg University, 5000LE Tilburg Netherlands \\ ${ }^{\mathrm{b}}$ CER-ETH - Center of Economic Research at ETH Zurich, Zürichbergstrasse 18, 8092 Zurich, Switzerland
}

\section{A R T I C L E I N F O}

\section{Article history:}

Received 2 July 2021

Revised 18 October 2021

Accepted 23 November 2021

Available online 2 December 2021

\section{JEL classification:}

E22

E41

E44

E52

016

\section{Keywords:}

Heterogeneous consumption preferences

Optimal policy

Zero lower bound

Negative interest rates

\begin{abstract}
A B S T R A C T
We study optimal policy design in a monetary model with heterogeneous preferences. In the model, financial markets are incomplete and households are heterogeneous with respect to their current consumption preferences and discount factors. The government controls the supply of money (liquid) and nominal bonds (illiquid), and households make optimal portfolio choices. We uncover that the two types of preference heterogeneity have distinct distributional consequences and different implications for the optimal monetary policy. While the heterogeneity in current consumption preferences pushes the economy towards a zero lower bound (ZLB) associated with nominal interest rates, the heterogeneity in discount factors moves the economy away from the ZLB. We characterize the optimal policy design and quantify the welfare losses associated with a binding ZLB - and thus also the potential welfare benefits of being able to implement negative interest rates.
\end{abstract}

(c) 2021 The Author(s). Published by Elsevier B.V. This is an open access article under the CC BY license (http://creativecommons.org/licenses/by/4.0/)

\section{Introduction}

An extensive quantitative-macro literature studies cross-sectional variance of consumption over the life-cycle. ${ }^{1}$ Some papers in this line of research highlight the relevance of heterogeneous preferences (mainly in the form of discount factor shocks) in accounting for variance in consumption. ${ }^{2}$ Preference heterogeneity may exacerbate inequality and cause welfare losses when financial markets are incomplete ${ }^{3}$ or when fiscal policy is set sub-optimally. ${ }^{4}$

In this paper, we approach the interaction between preference heterogeneity and consumption variability over the lifecycle from a different perspective: To what extent can monetary policy correct the distributional consequences of heterogeneous preferences and improve welfare when markets are incomplete? There are two main contributions of our paper to the literature. First, we take a general stance on modeling life-cycle consumption preferences allowing to match empirically ob-

\footnotetext{
sy we would like to thank two anonymous referees and the editor, B. Ravikumar, for their comments and recommendations. We also thank Aleksander Berentsen, Francesco Carli, Pedro Gomis-Porqueras, Mariana Rojas-Breu, and Florian Sniekers for valuable discussions, and recommendations on this topic. Finally, we thank seminar participants at Tilburg University and the University of Basel. All remaining errors are ours.

* Corresponding author.

E-mail addresses: r.b.uras@uvt.nl (B.R. Uras), hvanbuggenum@ethz.ch (H. van Buggenum).

1 See De Nardi and Fella (2017) for an extensive survey of the literature and Deaton and Paxson (1994) and Aguiar and Hurst (2013).

2 Krusell and Smith (1998), Venti and Wise (2000), Cagetti (2003), and Gelman (2021).

3 Krusell and Smith (1998) and Hendricks (2007).

4 Golosov et al. (2013).
} 
served variation in life-cycle consumption. Second, our model embeds a particular timing friction such that the no-arbitrage condition between money and nominal bonds fails to hold, based on which we characterize the optimal inflation and bond interest rate policies of the government.

More specifically, we incorporate in our model intra-generational heterogeneity with respect to both current marginal utility to consume and discount factors. Therefore, our set-up is also suitable to potentially account for the empirically observed cross-sectional variance of consumption over the life-cycle. Based on this framework, we argue that optimal monetary policy needs to influence both the price of liquid (money, i.e. inflation) and illiquid (bonds, i.e. nominal interest rates) assets to achieve an optimal cross-sectional allocation of consumption and wealth over the life-cycle. We also characterize the conditions for an endogenous zero lower bound (ZLB) on nominal interest rates to bind. We find that the ZLB limits optimal policy and results in welfare losses.

Our benchmark framework is a dynamic general equilibrium model of a monetary economy with three-period lived households who are connected over time through overlapping generations. At the beginning of the life-cycle, before preference shocks are revealed, households accumulate liquid assets by means of production. During the remainder of their lifetime, the households consume and re-balance liquid and illiquid assets by transacting in a financial market. We define the notion of an asset's liquidity based on the exchangeability of that asset in return for consumption goods in the current period. As is standard in monetary models, we assume that a special nominal object, called money, is the sole liquid asset available to the economy. Illiquid nominal assets, called bonds, serve as a saving instrument between periods. Important for our analysis is that the supplies of money and bonds are determined by the government.

At the core of our theoretical design are idiosyncratic preference shocks to which households are exposed in the second (early) and third (late) period of their life. We take a general approach in modeling this heterogeneity; there is a preference distribution to consume early as well as late, and individual preferences get realized at the beginning of the second period of households' lifetime. Early consumption preference (current marginal utility to consume) of a household is not necessarily correlated with its preference to consume late (the discount factor). Moreover, preference shocks are private information and therefore uninsurable; there is no market for idiosyncratic state-contingent claims. Given this market incompleteness, the heterogeneity of preferences gives rise to an environment in which over- or under-supply of (il)liquidity can prevail when inflation and nominal interest rates follow the Friedman rule - equating the real return on all assets to the natural rate of interest. The key theoretical analysis of our paper concentrates on exploring the optimal policy design that takes the distribution of consumption preferences as given.

As a primarily important result, we characterize a closed-form test statistic resulting from the distribution of preferences. We show that when a condition governed by this statistic is met, an endogenous ZLB on nominal interest rates gets reached. This ZLB arises because besides bonds, households can use money as a savings instrument. Our test statistic has a simple economic interpretation, as it characterizes the aggregate fraction of disposable resources that middle-aged households devote to early consumption. The properties that we obtain with regard to this test statistic are straightforward. On the one hand, when households are relatively heterogeneous in terms of their preference to consume early (current MU) and not that heterogeneous with respect to late consumption preferences (discount factors) - the test statistic is low and the economy reaches the ZLB. On the other hand, as heterogeneity in discount factors increases - while early consumption heterogeneity declines - the test statistic increases and the economy moves away from the ZLB. In this respect, our analysis reveals that increasing heterogeneity of impatience (current MU) and patience (discount factors) have different consequences for government's ability to freely choose an optimal nominal interest rate in its policy mix.

We then study the optimal policy design with respect to inflation and interest rates, and obtain an important property of the ZLB. That is, with a binding ZLB constraint a deviation from the Friedman rule becomes an optimal monetary policy choice. The intuition for this property is the following. When early consumption preferences are disperse (relative to the dispersion observed in discount factors) those agents with low MU to consume early like to increase savings, which pushes the aggregate savings rate to an inefficiently high level. In order to reduce this saving inefficiency and to stimulate early consumption of those with high MU, the government ideally reduces nominal interest rates to discourage late consumption and also reduces inflation, which raises the real value of the middle-aged their wealth, to encourage early consumption. However, reductions in nominal rates are infeasible beyond the ZLB, at which point increasing inflation becomes the optimal policy.

The reason for this important property relates to compounded costs of inflation, which affect late consumption more than early consumption. On the flip-side of the same channel, when discount factor shocks are relatively disperse (compared to the heterogeneity in early consumption preferences), the aggregate savings rate tends to contract. In order to stimulate late consumption the optimal policy increases the nominal interest rate - moving the economy away from the ZLB - and to discourage early consumption the optimal policy increases inflation to reduce the middle-aged their real wealth.

Based on our theoretical insights, we conduct a series of quantitative experiments using a parameterized version of the model. A counterfactual analysis reveals that, on the one hand, when the relative standard deviation of first-best early consumption equals one (as a benchmark case), the optimal policy increases steady state welfare by $0.6 \%$ of the first-best level of welfare. On the other hand, when the relative standard deviation of first-best late consumption equals one (as another benchmark), the optimal policy increases steady state welfare by $1.2 \%$ of the first-best level of welfare. This quantitatively substantial difference is caused by the fact that the ZLB binds in the former case but not in the latter. To further asses the impact of the ZLB, we conduct an experiment in which we remove the ZLB and allow for negative interest rates by forbid- 
ding the use of cash as a savings vehicle. We find that this raises aggregate welfare by $1.9 \%$ of first-best welfare when the relative standard deviation of first-best early consumption equals one.

To further discipline our model, we use US data on life-cycle consumption for calibration purposes. We find that in our calibrated model, the ZLB binds and the optimal policy involves a deflation of $-1.74 \%$. We also show that the welfare loss associated with the binding ZLB constraint is $1.23 \%$ of first-best output and the welfare loss associated with implementing the Friedman rule is $0.36 \%$ of first-best output.

As an important extension to the benchmark, we allow for private capital formation by households via a decreasing returns to scale investment technology. In the extended framework, we allow claims on capital to be traded as an illiquid asset to compete with government bonds. This extension reveals that endogeneous capital formation does not change the theoretical property associated with the threshold to reach the ZLB. A high spread in early consumption shocks causes the ZLB to bind, also with endogenous capital formation, at which the government remains with only inflation as a policy instrument - leading to distorted allocations. A high spread in discount factors moves the economy away from the ZLB. The main difference compared to the benchmark model is that with private capital - even away from ZLB - optimal policies are closer to the Friedman rule, as the latter achieves first-best levels of capital formation.

Our results imply that understanding the type of preference heterogeneity is important for optimal policy design. The findings reveal that uninsurable early consumption heterogeneity is likely to push an economy to the ZLB, constraining the capacity of monetary policy to maximize welfare. We also suggest the optimality of using money and bond pricing policies of the government in tandem and thus propose a new micro-foundation for the coexistence of money and bonds. Furthermore, given the constraining effects of the ZLB, we uncover a beneficial effect of being able to implement negative interest rates.

The remainder of this paper develops as follows. Section 2 briefly discusses the related literature. Section 3 develops the baseline model and analyzes optimal policy. Section 4 considers some quantitative experiments for our baseline model. Section 5 extends the baseline model with capital formation and Section 6 concludes. Figures can be found in Appendix A, and proofs and derivations can be found in Appendix B.

\section{Related literature}

Our paper speaks to several strands of literature. First, we contribute to the literature that models preference heterogeneity and cross-sectional consumption variation in quantitative macro models. Starting with the seminal work by Krusell and Smith (1998), there has been an interest to understand the role of discount factor shocks in explaining cross-sectional distributions of savings and wealth (Cagetti, 2003; Gelman, 2021; Venti and Wise, 2000) as well as asset prices (Gârleanu and Panageas, 2015). Most papers in this line of research document that - especially in the presence of incomplete markets - a small dispersion in discount factor heterogeneity across households, can be key to explain the data. We also relate to the branch that documents cross-sectional variation over-the life-cycle (Aguiar and Hurst, 2013; Deaton and Paxson, 1994). Our contribution to this literature is three-fold. (i) We develop a life-cycle monetary model that allows the independent determination of two monetary policy instruments (the inflation rate and the nominal interest rate) in a quantifiable life-cycle framework with heterogeneous preferences. (ii) Our analysis reveals that the implications of early and late consumption shocks are quite different from each other with respect to the welfare effects of optimally conducted monetary policy. (iii) Finally, we uncover the effects of preference heterogeneity on the ZLB and discuss optimality of negative interest rates.

Second, we also contribute to the literature on general equilibrium monetary models with preference heterogeneity. For instance, in a recent paper Curran and Dressler (2019) study the welfare implications of inflation in a model with heterogeneous coefficients of relative risk aversion. In four closely related papers, Berentsen et al. (2005), Bhattacharya et al. (2005), Boel and Camera (2006), and Boel and Waller (2019) embed heterogeneous preferences in new monetarist style models to study distributional consequences of monetary policy and - similar to our conclusions - argue for non-optimality of the Friedman rule under particular parameter constellations. However, there are two essential differences between our approach and these studies: (i) we take a more generalized approach in modeling preference heterogeneity (with respect to incorporating heterogeneity in both current consumption preferences and discount factors), and (ii) our approach allows to uncover the differential impact of the two different margins of preference shocks on coexistence of money and bonds, the ZLB, and optimality of negative interest rates.

Third, we relate to those models which stem from the Diamond and Dybvig (1983) framework with preference heterogeneity and which extend this model to an infinite horizon set-up with overlapping generations exhibiting life-cycle features. Seminal examples in this line of research, are Bencivenga and Smith (1991), Qi (1994), Bhattacharya and Padilla (1996), and Martin et al. (2014a, 2014b). The important difference between our paper and this line of research is that while these papers mainly concentrate on allocations with banks and markets under preference heterogeneity and in an environment with real financial instruments, we study the optimal design of monetary policy in a nominal setting with heterogeneous preferences over the life-cycle.

Fourth, we also contribute to a literature that studies optimal coexistence of money and bonds. Kocherlakota (2003) shows that in an infinite horizon economy, society can benefit from having both money and bonds when agents face shocks to marginal utility of current consumption. The mechanism identified by Kocherlakota (2003) is however transitory; welfare effects of introducing bonds last for one period only. Andolfatto (2011) demonstrates that the transitory mechanism of Kocherlakota (2003) persists in steady state when implementing the Friedman rule is infeasible. 
Van Buggenum (2021) considers an infinite horizon economy in which agents experience shocks to their subjective discount factors and shows that even when the Friedman rule is implementable, interest bearing bonds are essential to achieve an efficient distribution of savings. In an OLG framework with shocks to both the marginal utility from current consumption and subjective discount factors, the current paper demonstrates that bonds are essential when discount factor shocks dominate in characterizing preference heterogeneity. Moreover, we also analyze the welfare implications of a ZLB on nominal interest rates earned by bonds.

Fifth, our work contributes to the literature pioneered by Zhu (2008), who re-casted the money-search model of Lagos and Wright (2005) in an infinite horizon environment with overlapping generations of two-period lived agents. As in Zhu (2008), the OLG nature of our model allows us to incorporate tractable wealth effects while our approach rests upon different structural assumptions. Importantly, our model of three-period lived agents implies that the optimal policy influences not only the price of liquid assets - inflation - but also that of illiquid assets - nominal interest rates. In this respect, we also follow Hiraguchi (2017), who introduces illiquid capital in the model of Zhu (2008), to study how optimal policies are affected by the presence of such capital. In line with Hiraguchi's (2017) results, we find that with illiquid capital the optimal policy deviates from the Friedman rule. Moreover, the nature of our setup implies additional insights, as we uncover that illiquid capital affects only the optimal inflation (nominal interest) rate when the ZLB constraint is binding (resp. slack). Gomis-Porqueras and Waller (2017) study the role of the government's information set for the optimal monetary and fiscal policy, as well as the substitutability of the two, in the model of Zhu (2008). We take the government's information set as given, but note that fiscal policy can be used as a substitute for monetary policy when the government can levy an age-contingent consumption or savings tax.

Finally, several recent papers in the monetary macro literature have argued for the optimality of negative interest rates, such as Dong and Wen (2017) and Williamson (2019) - following the trends in interest rates in some European countries. Our paper is the first in this literature that uncovers a mechanism related to heterogeneity in preferences in justifying the conduct of optimal negative interest rate policies.

\section{Benchmark model}

We study an overlapping generations model with three-period lived households. We refer to the households as young in the first period of their lifetime, and as middle-aged and old in the second and third period, respectively. There are three types of objects in the economy: a non-storable consumption good, and two nominal assets that we label as money and bonds. The supply of money and bonds are determined by the government. The consumption good is produced by the young, and consumed by the middle-aged and old.

During each time period, two markets open sequentially in two distinct sub-periods that allow trade of assets and consumption goods: the financial market (FM) and the goods market (GM). The consumption good is produced and sold in the GM by the young and it fully perishes within a time period. Money is the only recognizable object in the GM, so bonds cannot be traded in this sub-period. The unit-price of the consumption good in the GM is $p_{t}$ - denoted in terms of money.

In the FM, money and bonds are supplied by the government and the two objects are traded among households. Money is storable across time, while bonds issued in the FM of period $t$ mature in period $t+1$ and pay out money. The unit price of bonds is $\varphi_{t}$ - denoted in terms of fiat money. ${ }^{5}$ In the FM, the government also levies lump-sum taxes on middle-aged households (or provides the middle-aged with lump-sum subsidies), which are paid with money. There is no enforcement problem with respect to the payment of taxes, but preferences are private information so the government cannot condition taxes on households' preferences. ${ }^{6}$ We denote with $M_{t}$ the aggregate money supply after the FM has convened, and with $B_{t}$ the nominal face value of bonds issued in period $t$. The real consumption good equivalent of the lump-sum tax is denoted with $\tau_{t}$ and satisfies

$$
p_{t} \tau_{t}=B_{t-1}+M_{t-1}-\varphi_{t} B_{t}-M_{t}
$$

Lifetime preferences of a household are given by

$$
\mathcal{U}_{\xi}\left(h, q_{\xi}^{m}, q_{\xi}^{o}\right)=-h+\beta \varepsilon u\left(q_{\xi}^{m}\right)+\beta^{2} \delta u\left(q_{\xi}^{o}\right) .
$$

In preference specification (2), $h$ denotes production of goods when young, ${ }^{7} q_{\xi}^{m}$ denotes consumption of goods when middleaged, i.e. early consumption, and $q_{\xi}^{o}$ denotes consumption when old, i.e. late consumption. Parameter $\beta$ is a component of the discount factor that is common to all households. Important for our model, are idiosyncratic preference shocks that households are subject to. Specifically, at the beginning of the second period of their lifetime, each middle-aged household

\footnotetext{
${ }^{5}$ Given the structure of our model, the focus on one-period bonds is without loss of generality. As long as bonds are tradable in the FM, i.e. before maturity, a no-arbitrage condition will namely imply that all bonds, regardless of when they mature, will earn the same return when held from time $t$ to time $t+1$. In a more complicated environment with agents living for many periods, it may be the case that the optimal return on savings depends agents' age. Then, to have a non-flat yield curve, a government would introduce bonds with different maturities which cannot be traded prior to maturity. Furthermore, our main insight would remain valid: The optimal policy depends on the type of preference heterogeneity.

${ }^{6}$ When the government would be able to levy taxes contingent on households' preferences, the financial market incompleteness laid out in the introduction can be eliminated fully and first-best allocations are achieved.

7 The linear dis-utility for labor eases the analysis and is not critical for our results.
} 
draws a tuple $\xi=(\varepsilon, \delta)$ from a distribution with $\operatorname{CDF} G(\varepsilon, \delta)$ and support $\Xi \in \mathbb{R}_{+}^{2}$. In this joint preference distribution, $\varepsilon$ is an idiosyncratic preference shifter for early consumption and $\delta$ is an idiosyncratic preference shifter for late consumption which get realized simultaneously. We remain agnostic about $G$, which means $\varepsilon$ could exhibit negative or positive correlation with $\delta$. Without loss of generality, we make the following assumption.

Assumption 1. $\mathbb{E}[\varepsilon]=\mathbb{E}[\delta]=1$.

The preference shocks serve to generate intra-generational heterogeneity across households, the equilibrium implications of which constitute the core analysis of this paper. To ensure that the preference shocks are uninsurable, we impose that the shocks are private information and that households can only work when young. ${ }^{8}$

\subsection{Equilibrium analysis}

We denote gross inflation in between periods $t-1$ and $t$ with $\pi_{t}=p_{t} / p_{t-1}$, which in steady state equals the growth rate of money supply. Because money is a store of value, and the nominal bonds pay out money, households do not hold bonds when the interest rate on bonds is negative $(\varphi>1)$. Hence, the effective gross real interest rate at which middle-aged households can save equals $1 /\left[\min \left\{\varphi_{t+1}, 1\right\} \pi_{t+2}\right]$.

Households are born only with a labor endowment, which they can use to accumulate money in the GM. When young, households however cannot participate in the FM, as this market convenes before the GM. ${ }^{9}$ In the GM, a young household can accumulate money balances by producing consumption goods and selling them at nominal price $p_{t}$. When turning middle aged in the next period, the household first learns the realization of its preference shock $\xi$ and pays the lump-sum tax $p_{t+1} \tau_{t+1}$ (expressed in nominal terms). Then, the household can acquire bonds in the FM at a nominal price $\varphi_{t+1}$ and it can trade money for real consumption goods in the GM at nominal price $p_{t+1}$. When old, during the FM a household redeems the bonds accumulated when middle-aged and then consumes all remaining money balances in the GM, where consumption goods trade at nominal price $p_{t+2}$. Taking into account the effective gross real interest rate at which middleaged households can save, lifetime utility maximization of a household born in period $t$ therefore implies

$$
\begin{aligned}
& \mathcal{U}_{t}=\max _{h_{t},\left\{q_{\xi, t}^{m}, q_{\xi, t}^{o}\right\}_{\xi \in \Xi}}\left\{-h_{t}+\beta \mathbb{E}\left[\varepsilon u\left(q_{\xi, t}^{m}\right)\right]+\beta^{2} \mathbb{E}\left[\delta u\left(q_{\xi, t}^{o}\right)\right]\right\} \\
& \text { s.t. } \quad \pi_{t+1}\left[q_{\xi, t}^{m}+\min \left\{\varphi_{t+1}, 1\right\} \pi_{t+2} q_{\xi, t}^{o}+\tau_{t+1}\right] \leq h_{t}, \quad \forall \xi \in \Xi .
\end{aligned}
$$

where $(3 a)$ is the expected life-time utility and (3b) is a state-contingent resource constraint. It follows that the amount of money $M_{\xi, t}^{m}$ and bonds $B_{\xi, t}^{m}$ carried out of the FM by a middle-aged household born in period $t$, satisfies

$$
M_{\xi, t}^{m}+\varphi_{t+1} B_{\xi, t}^{m}=p_{t+1} q_{\xi, t}^{m}+p_{t+2} \min \left\{\varphi_{t+1}, 1\right\} q_{\xi, t}^{o} \quad \text { and } \quad B_{\xi, t}^{m} \begin{cases}=p_{t+2} q_{\xi, t}^{o} & \text { if } \varphi_{t+1}<1 \\ \in\left[0, p_{t+2} q_{\xi, t}^{o}\right. & \text { if } \varphi_{t+1}=1 \\ 0 & \text { if } \varphi_{t+1}>1\end{cases}
$$

Similarly, the amount of money $M_{\xi, t}^{o}$ and bonds $B_{\xi, t}^{o}$ carried out of the FM by an old-aged household born in period $t$ satisfies

$$
M_{\xi, t}^{o}=p_{t+2} q_{\xi, t}^{o} \quad \text { and } \quad B_{\xi, t}^{o}=0
$$

The initial middle-aged and old in period $t=0$ cannot supply labor, but are instead endowed with, respectively, $M^{m}$ and $M^{o}$ units of money just before the FM convenes. The initial middle-aged therefore solve

$$
\begin{aligned}
& \mathcal{U}_{-1, \xi}=\max _{q_{\xi,-1}^{m}, q_{\xi,-1}^{o}}\left\{\varepsilon u\left(q_{\xi,-1}^{m}\right)+\beta \delta u\left(q_{\xi,-1}^{o}\right)\right\} \\
& \text { s.t. } \quad p_{0}\left[q_{\xi,-1}^{m}+\min \left\{\varphi_{0}, 1\right\} \pi_{1} q_{\xi,-1}^{o}+\tau_{0}\right] \leq M^{m},
\end{aligned}
$$

and the initial old-aged simply consume their endowment:

$$
p_{0} q_{\xi,-2}^{o}=M^{0}, \quad \forall \xi \in \Xi .
$$

Assets carried out of initial FM by the middle aged - $M_{-1}^{m}$ and $B_{-1}^{m}$ - and by the initial old - $M_{-2}^{o}$ and $B_{-2}^{o}{ }^{-}$, satisfy Eqs. (4) and (5). We then define the concept of the equilibrium as follows.

\footnotetext{
${ }^{8}$ We can let households work when middle-aged, but then we need that devoting labor effort when middle-aged is less attractive or limited compared to devoting labor effort when young. For simplicity, we therefore focus on a case in which households only work when young.

${ }^{9}$ This assumption implies that labor income earned by the young is subject to an inflation tax, which cannot be avoided by holding interest-bearing bonds. This is a structural assumption which we introduce to the model as in models from the cash-in-advance literature. As a result, nominal interest rates in our economy only affect the return on saving between middle-aged and old. Alternatively if we would have allowed the GM and FM to convene simultaneously, in order to achieve the same theoretical mechanism we could have introduced illiquid bonds with different maturities to partially replicate our current environment in which young households cannot avoid the inflation tax. One way of achieving this property would be by reducing the interest rate on short-term bonds relative to that on long-term bonds.
} 
Definition 1. Given a policy $\left\{M_{t}, B_{t}, \tau_{t}\right\}_{t=0}^{\infty}$ with $\tau_{t}$ given by Eq. (1), as well as $M^{m}$ and $M^{o}$ units of money that, respectively, the initial middle-aged and old households are endowed with, equilibrium is a sequence of allocations $\left\{h_{t},\left\{q_{\xi, t-1}^{m}, q_{\xi, t-2}^{o}\right\}_{\xi \in \Xi}\right\}_{t=0}^{\infty}$, asset holdings $\left\{\left\{M_{\xi, t-1}^{m}, M_{\xi, t-2}^{o}, B_{\xi, t-1}^{m}, B_{\xi, t-2}^{o}\right\}_{\xi \in \Xi}\right\}_{t=0}^{\infty}$, and prices $\left\{p_{t}, \varphi_{t}\right\}_{t=0}^{\infty}$ such that:

1. Households maximize utility; $\left\{h_{t},\left\{q_{\xi, t}^{m}, q_{\xi, t}^{o}\right\}_{\xi \in \Xi}\right\}$ maximizes objective function (3a) subject to the state-contingent budget constraint (3b) for all $t \geq 0,\left\{q_{\xi,-1}^{m}, q_{\xi,-1}^{o}\right\}_{\xi \in \Xi}$ maximizes objective function (6a) subject to budget constraint (6b), $\left\{q_{\xi,-2}^{o}\right\}_{\xi \in \Xi}$ satisfies Eq. (7), and $\left\{\left\{M_{\xi, t-1}^{m}, M_{\xi, t-2}^{o}, B_{\xi, t-1}^{m}, B_{\xi, t-2}^{o}\right\}_{\xi \in \Xi}\right\}_{t=0}^{\infty}$ satisfies Eqs. (4) and (5).

2. The FM clears; for all $t$ we have that $M_{t}=\iint\left[M_{\xi, t-1}^{m}+M_{\xi, t-2}^{o}\right] \mathrm{d} G(\varepsilon, \delta)$ as well as $B_{t}=\iint\left[B_{\xi, t-1}^{m}+B_{\xi, t-2}^{o}\right] \mathrm{d} G(\varepsilon, \delta)$.

3. The GM clears; for all $t$ we have that $h_{t}=\iint\left[q_{\xi, t-1}^{m}+q_{\xi, t-2}^{o}\right] \mathrm{d} G(\varepsilon, \delta)$.

To obtain closed-form and intuitive solutions, we assume $\operatorname{logarithmic~utility~such~that~} u(q)=\log (q)$ for both middle-age and old households. The virtue of assuming logarithmic utility is that a middle-aged household spends a fraction of its budget on early consumption that depends only on the household's type-specific preferences. This allows us to link optimal policies to the average marginal propensity to consume across middle-aged households.

Based on the chosen functional form for preferences, we first observe that labor supply by the young satisfies

$$
h_{t}=\beta(1+\beta)+\pi_{t+1} \tau_{t+1},
$$

where $\beta(1+\beta)$ hours of work are used to provide resources for early and late consumption, and $\pi_{t+1} \tau_{t+1}$ hours are provided to pay lump-sum taxes when middle-aged.

Furthermore, early and late consumption are given by:

$$
q_{\xi, t}^{m}=\frac{\varepsilon}{\varepsilon+\beta \delta} \frac{\beta(1+\beta)}{\pi_{t+1}} \text { and } q_{\xi, t}^{o}=\frac{\beta \delta}{\varepsilon+\beta \delta} \frac{\beta(1+\beta)}{\min \left\{\varphi_{t+1}, 1\right\} \pi_{t+1} \pi_{t+2}}, \quad \text { for all } \xi \in \Xi .
$$

The levels of early and late consumption at (8) are negatively related to the level of inflation. Late consumption is negatively related to the price of bonds and is more sensitive to inflation than early consumption because of compounding.

As an important property of logarithmic utility, we obtain that only preference shifters and the common discount factor determine middle-aged households' desire to save. Specifically, after taxation middle-aged households have $\beta(1+\beta) / \pi_{t+1}$ units of real money balances available in the FM. They consume a fraction $\theta=\varepsilon /(\varepsilon+\beta \delta)$ of this sum in the GM and save the remaining fraction $1-\theta$ for consumption in the next period, earning a real rate of return $1 /\left[\min \left\{\varphi_{t+1}, 1\right\} \pi_{t+2}\right]$. We therefore define as a test statistic:

$$
\Theta \equiv \iint \frac{\varepsilon}{\varepsilon+\beta \delta} \mathrm{d} G(\varepsilon, \delta)
$$

The test-statistic defined at (9) is at the core of our policy analysis and measures the aggregate fraction of middle-aged households' disposable wealth devoted to early consumption. Analogously, $1-\Theta$ captures the aggregate savings rate of middle-aged households.

Aggregate demand for money $M_{t}$ and bonds $B_{t}$ in the FM of period $t$ is given by:

$$
\begin{aligned}
& \frac{M_{t}}{\beta(1+\beta) p_{t}} \begin{cases}=\frac{\Theta}{\pi_{t}}+\frac{1-\Theta}{\min \left\{\varphi_{t-1}, 1\right\} \pi_{t-1} \pi_{t}} & \text { if } \varphi_{t}<1 \\
\in\left[\frac{\Theta}{\pi_{t}}+\frac{1-\Theta}{\min \left\{\varphi_{t-1}, 1\right\} \pi_{t-1} \pi_{t}}, \frac{1}{\pi_{t}}+\frac{1-\Theta}{\min \left\{\varphi_{t-1}, 1\right\} \pi_{t-1} \pi_{t}}\right] & \text { if } \varphi_{t}=1, \\
=\frac{1}{\pi_{t}}+\frac{1-\Theta}{\min \left\{\varphi_{t-1}, 1\right\} \pi_{t-1} \pi_{t}} & \text { if } \varphi_{t}>1\end{cases} \\
& \frac{\varphi_{t} B_{t}}{\beta(1+\beta) p_{t}}= \begin{cases}\frac{1}{\pi_{t}}+\frac{1-\Theta}{\min \left\{\varphi_{t-1}, 1\right\} \pi_{t-1} \pi_{t}}-\frac{M_{t}}{\beta(1+\beta) p_{t}} & \text { if } \varphi_{t} \leq 1 \\
0 & \text { if } \varphi_{t}>1\end{cases}
\end{aligned}
$$

With a strictly positive supply of bonds, market clearing requires that $\varphi_{t} \leq 1$. An endogenous zero lower bound (ZLB) on nominal interest rates therefore arises. In what follows, without loss of generality we assume $\varphi_{t} \leq 1$.

We close the equilibrium analysis by solving for the lump-sum taxes and the labor supply of the young as a function of inflation, bond prices, and preference parameters. For this purpose, we equate labor supply by young to total consumption by the middle-aged and old in a particular time period: $h_{t}=\mathbb{E}\left\{q_{\xi, t-1}^{m}+q_{\xi, t-2}^{o}\right\}$. The solution leads us to determine:

$$
h_{t}=\beta(1+\beta)\left[\frac{\Theta}{\pi_{t}}+\frac{1-\Theta}{\varphi_{t-1} \pi_{t-1} \pi_{t}}\right] \text { and } \tau_{t}=\frac{\beta(1+\beta)}{\pi_{t}}\left[\frac{\Theta}{\pi_{t-1}}+\frac{1-\Theta}{\varphi_{t-2} \pi_{t-2} \pi_{t-1}}-1\right] \text {. }
$$

\subsection{Optimal policy}

As is standard in OLG models, we let welfare across generations be aggregated according to the subjective discount factor $\beta$. From Eqs. (10) and (11), it follows that any sequence of inflation rates and bond prices $\left\{\varphi_{t}, \pi_{t+1}\right\}_{t=0}^{\infty}$ subject to $\varphi_{t} \leq 1$ can be implemented as an equilibrium by choosing a sequence of policies $\left\{M_{t}, B_{t}\right\}_{t=0}^{\infty}$ in line with Eqs. (10) and (11).

Importantly, because of the OLG structure, the real interest rate that middle-aged earn on their savings for old-aged consumption is endogenous and depends on the supply of bonds. As a result, there is not a one-to-one relationship between 
inflation and nominal interest rates in our model. This feature allows policy to affect both middle-aged consumption, which is governed by inflation, and old-aged consumption, which is governed by the real return on savings, separately. Policy is however restricted in the sense that the real return on savings is bounded from below due to the endogenous ZLB on nominal interest rates.

To simplify the analysis, we focus on a policy maker with perfect commitment that maximizes

$$
\mathcal{W}_{t}=\sum_{s=t}^{\infty} \beta^{s-t}\left[\mathbb{E}\left\{\varepsilon u\left(q_{\xi, s-1}^{m}\right)\right\}+\mathbb{E}\left\{\delta u\left(q_{\xi, s-2}^{o}\right)\right\}-h_{s}\right]
$$

by choosing a sequence $\left\{\varphi_{s}, \pi_{s+1}\right\}_{s=t+1}^{\infty}$ subject to $\varphi_{s} \leq 1$ and taking as given $\left\{\varphi_{s}, \pi_{s+1}\right\}_{s=0}^{s=t}$. Here, we assume that the policymaker cannot choose $\pi_{t}, \pi_{t+1}$, and $\varphi_{t}$. These are variables that the young in periods $t-1$ and $t-2$ need for their decisions, so what the policymaker communicated in those periods about $\pi_{t}, \pi_{t+1}$, and $\varphi_{t}$ is what the policymaker has to commit to in periods $t, t+1, \ldots, \infty$.

Contrary to most analyses of OLG models, our policy maker's problem does not maximize welfare of a cohort born in steady state equilibrium. Instead, we maximize a welfare measure which is the weighted sum of utilities of all current and future generations, with a generation born in period $s$ receiving weight $\beta^{s-t}$. Importantly, the policy maker takes consumption levels, and thus utility, of the current middle-aged and old as given. This is reflected in the fact that the policymaker takes $\pi_{t}, \pi_{t+1}$, and $\varphi_{t}$ as given. Hence, contrary to the analysis of policies in OLG environments by Auernheimer (1974), our policies have no implications on the initial old and middle-aged.

Given the logarithmic utility specification, the welfare function at (13) can be expressed as:

$$
\mathcal{W}_{t}=\sum_{s=t}^{\infty} \beta^{s-t}\left\{\Delta-\log \left(\pi_{s}\right)-\frac{\Theta \beta(1+\beta)}{\pi_{s}}-\log \left(\varphi_{s-1} \pi_{s-1} \pi_{s}\right)-\frac{(1-\Theta) \beta(1+\beta)}{\varphi_{s-1} \pi_{s-1} \pi_{s}}\right\},
$$

where

$$
\Delta=\iint\left[\varepsilon \log \left(\frac{\varepsilon \beta(1+\beta)}{\varepsilon+\beta \delta}\right)+\delta \log \left(\frac{\delta \beta^{2}(1+\beta)}{\varepsilon+\beta \delta}\right)\right] \mathrm{d} G(\varepsilon, \delta) .
$$

Let $\beta^{s+1-t} \chi_{s}$ denote the Lagrange multiplier on the ZLB constraint for $\varphi_{s}$, which allows to obtain the following first-order conditions that maximize (14):

$$
\begin{aligned}
\pi_{s+2}: & 0=-\frac{2+\beta}{\pi_{s+2}}+\frac{\Theta \beta(1+\beta)}{\pi_{s+2}^{2}}+\frac{\beta(1+\beta)(1-\Theta)}{\varphi_{s+1} \pi_{s+1} \pi_{s+2}^{2}}+\frac{\beta^{2}(1+\beta)(1-\Theta)}{\varphi_{s+2} \pi_{s+2}^{2} \pi_{s+3}}, \\
\varphi_{s+1}: & 0=-\chi_{s+1}-\frac{1}{\varphi_{s+1}}+\frac{\beta(1+\beta)(1-\Theta)}{\varphi_{s+1}^{2} \pi_{s+1} \pi_{s+2}} .
\end{aligned}
$$

Focusing on steady state policies and using that complementary slackness implies $\chi_{s} \varphi_{s}=\chi_{s}$, Eqs. (16) and (17) reduce to:

$$
\pi=\Theta \beta(1+\beta)+\chi \pi(1+\beta) \text { and } \varphi \pi^{2}=\beta(1+\beta)(1-\Theta)-\chi \pi^{2} .
$$

The closed-form test statistic $\Theta$ has a crucial implication for the ZLB constraint, which we summarize in the next lemma.

Lemma 1. The ZLB constraint binds if and only if $\Theta(1+\beta)<1$.

Recall that $\theta=\varepsilon /(\varepsilon+\beta \delta)$ and $\Theta=\mathbb{E}[\theta]$, and then note that $\theta$ is concave in $\varepsilon$ and convex in $\delta$. On the one hand, as shocks to early consumption become more disperse, $\Theta$ decreases. On the other hand, the dispersion in late consumption preferences increases the value of $\Theta$. These comparative statics with respect to $\Theta$ imply that enlarging heterogeneity in early and late consumption preferences have clear-cut and opposing effects with respect to the distance of an economy to the ZLB and the ability of the government to choose an unconstrained policy mix in steady state equilibrium.

As benchmark for policy, we consider the Friedman rule.

Definition 2. The Friedman rule sets $\pi=\beta$ and $\varphi=1$ so that the real return on all assets equals the natural rate of interest, $1 / \beta$.

By letting the return on all assets equal the natural rate of interest, defined by the inverse of the average discount factor $\beta$, our definition of the Friedman rule aligns with the optimal policy in an environment without preference heterogeneity. The reason is that it removes the opportunity cost associated with holding money. Moreover, as we show explicitly in Section 4, the Friedman rule also implements the first-best allocations in a complete financial market structure with observable and insurable preference shocks.

When early consumption preferences are disperse, we find that, ceteris paribus, the aggregate savings rate increases and that an optimal policy responds to this. The reason for the change in savings lies in the diminishing effect of increasing the MU from early consumption on the fraction of resources that middle-aged devote to early consumption. Intuitively, for households with a high MU shock to early consumption, the fraction of resources devoted to early consumption is already close to 1 - the theoretical maximum for $\theta$. A further increase in the realization of this MU shock, which would arise when the dispersion of early consumption preferences increases, thus has only a small effect on $\theta$. 
For households with a low marginal utility shock to early consumption, the fraction of resources devoted to early consumption is however low. Hence, the bare-bone MU from early consumption - $u^{\prime}\left(q_{\xi}^{m}\right)$ - is large for these households. Ceteris paribus, a decrease in the multiplicative shock to MU, which would arise following an increase in the dispersion of early consumption preferences, therefore has a large effect on their actual MU from early consumption. Therefore, these households respond by shifting a relatively large fraction of their resources away from early consumption.

Summarizing, increasing the dispersion of early consumption preferences leads to a relatively large increase (small decrease) in savings by households that care relatively little (resp. much) about early consumption thus shifting the distribution of $\theta$ to the left and leading to an inefficiently high aggregate savings rate. In order to stimulate early consumption and discourage late consumption, relative to the allocations implied by the Friedman rule, inflation and nominal rates would then have to be reduced in tandem. The reason is that reducing inflation raises the real value of middle-aged agents' wealth. This has a positive effect on middle-aged consumption, but also on old-aged consumption. To counteract the positive effect of lower inflation on old-aged consumption and instead achieve lower equilibrium levels of old-aged consumption, the nominal interest rate would have to be reduced.

However, because of the ZLB, interest rates cannot be reduced to take values in the negative domain. Therefore, at ZLB, increasing the inflation becomes part of the (constrained) optimal policy mix of the government. The intuition for this surprising result relates to the compounded effects of inflation, which we observe in Eq. (8): inflation reduces late consumption more than early consumption. As we will quantitatively evaluate in the next section, constrained optimal policy results in output and welfare losses - relative to an unconstrained optimum with negative interest rates on nominal bonds.

When discount factor shocks are relatively disperse (compared to the heterogeneity of early consumption preferences), for similar reasons as discussed before, the distribution of $\theta$ shifts to the right. This leads to inefficiently high early consumption at the Friedman rule. To correct for this, inflation and nominal interest rates should both increase in tandem in the optimal policy mix of the government: To reduce middle-aged consumption the inflation rate increases, but this also has a negative effect on old-aged consumption. To counteract this negative effect and stimulate old-aged consumption instead, the nominal rate should increase. Hence, the economy moves away from the ZLB.

The qualitative properties that we obtained with respect to the effects of preference dispersion on the tightness of the ZLB, yield the following characterization of the optimal policy in steady state.

Proposition 1. The optimal policy mix in a steady state equilibrium satisfies:

$$
\begin{aligned}
& \varphi=\left\{\begin{array}{ll}
1 & \text { if } \Theta(1+\beta)<1 \\
\frac{1-\Theta}{\Theta^{2} \beta(1+\beta)} & \text { if } \Theta(1+\beta) \geq 1
\end{array},\right. \\
& \pi=\left\{\begin{array}{ll}
(1+\beta) \frac{\Theta \beta+\sqrt{\beta} \sqrt{\beta \Theta^{2}+4(2+\beta)(1-\Theta)}}{2(2+\beta)} & \text { if } \Theta(1+\beta)<1 \\
\Theta \beta(1+\beta) & \text { if } \Theta(1+\beta) \geq 1
\end{array},\right.
\end{aligned}
$$

where the inflation rate when the ZLB binds, is the positive root of the following polynomial:

$$
(2+\beta) \pi^{2}-\Theta \beta(1+\beta) \pi-\beta(1+\beta)^{2}(1-\Theta)=0 .
$$

These key results imply that while increasing the heterogeneity in current consumption preferences constrains the policy choice set of the government, raising the discount factor heterogeneity improves the freedom of the government in choosing a welfare maximizing optimal policy. We follow up on this proposition with a corollary to summarize the implications of preference heterogeneity on optimal inflation, which also follows from the basic intuition related to the effects of preference heterogeneity on the tightness of the ZLB.

Corollary 1. The optimal inflation rate satisfies $\pi \geq \beta$, with equality if and only if $\Theta(1+\beta)=1$. With no idiosyncratic shocks to preferences, or when there are preference shocks but such that $\Theta(1+\beta)=1$, the optimal inflation rate is at the Friedman rule. In the absence of the endogenous zero lower bound constraint, $\pi<\beta$ would be an optimal inflation policy when $\Theta(1+\beta)<1$.

The fact that we find a strictly positive optimal nominal interest rate when our test statistic satisfies $\Theta(1+\beta)>1$, points towards the welfare enhancing role of bonds in our environment. With nominal rates at the ZLB, bonds and money become perfect substitutes. When the ZLB constraint binds, the policymaker can therefore attain its desired allocations by only supplying money to the economy. However, when $\Theta(1+\beta)>1$, the policymaker chooses allocations that, to be implemented as equilibrium outcomes, require a strictly positive supply of both money and bonds. In this sense, bonds are essential for welfare and our analysis reveals that the financial friction which results in a failure of the no-arbitrage condition between money and nominal bonds, meaning that money and interest-bearing bonds can coexist, is welfare improving. Specifically, the inability of young agents to access the financial market immediately after production allows the government to utilize two policy instruments (inflation and the nominal interest rate) independently from each other, which makes policy more flexible.

When a policy maker would be unable to supply bonds, we obtain allocations similar to those in an economy in which the policymaker faces the constraint $\varphi=1$. It follows from Proposition 1 that the optimal inflation rate is then given by the positive root of the polynomial in Eq. (21). If and only if $\Theta(1+\beta)>1$, this rate of inflation differs from that in an economy where the policymaker can also supply bonds, i.e. only faces the constraint $\varphi \leq 1$. We summarize these findings in a corollary: 
Corollary 2. The optimal inflation rate in an economy with only money is given by the positive root of the polynomial in Eq. (21). Optimized aggregate welfare when the policymaker is able to supply both money and bonds is higher than optimized welfare when the policymaker is only able to supply money, and strictly higher when the ZLB constraint is slack; $\Theta(1+\beta)>1$.

Finally, we characterize the steady state levels of output and taxation under the optimal policy:

Corollary 3. Define $g(\Theta)=\beta \Theta+\sqrt{\beta} \sqrt{\beta \Theta^{2}+4(2+\beta)(1-\Theta)}$. Given the optimal steady state policy mix, steady state output (as measured by labor supply) satisfies

$$
h= \begin{cases}\frac{2 \beta(2+\beta)}{g(\Theta)}\left[\Theta+\frac{2(2+\beta)(1-\Theta)}{(1+\beta) g(\Theta)}\right] & \text { if } \Theta \beta(1+\beta)<1 \\ 2 & \text { if } \Theta \beta(1+\beta) \geq 1\end{cases}
$$

and steady state taxation satisfies

$$
\tau=\left\{\begin{array}{ll}
\frac{\beta}{1+\beta}\left[\frac{2(2+\beta)}{g(\Theta)}\right]^{2}\left[\Theta+\frac{2(2+\beta)(1-\Theta)}{(1+\beta) g(\Theta)}\right]-\frac{2 \beta(2+\beta)}{g(\Theta)} & \text { if } \Theta \beta(1+\beta)<1 \\
\frac{2-\beta(1+\beta)}{\Theta \beta(1+\beta)} & \text { if } \Theta \beta(1+\beta) \geq 1
\end{array} .\right.
$$

Here, it can be shown that output $h$ is strictly increasing in $\Theta$ when the ZLB binds and is constant when the ZLB is slack. Output thus reduces as a result of the binding ZLB constraint. Taxation is strictly increasing in $\Theta$ when the ZLB is binding and strictly decreasing in $\Theta$ when the ZLB is slack. As a result, taxation is always reducing in inflation, even when inflation moves in tandem with the nominal interest rate, which is the case for a slack ZLB constraint. With the ZLB slack, taxation is always positive but with a binding ZLB constraint, when $\Theta$ is sufficiently small taxation becomes negative.

\subsection{Qualitative illustration of optimal policy}

In order to conclude the qualitative discussions resulting from the benchmark model, we turn towards illustrating optimal policy design for some special cases with respect to the heterogeneity in preferences. First we discuss the case of no preference shocks or policy neutral shocks. Suppose there is no intra-generational heterogeneity of preferences, meaning there are no idiosyncratic preference shocks and $\Theta(1+\beta)=1$. In this case, like in standard micro-founded models of money, the Friedman rule is optimal. The same optimal policy prevails also when there is preference heterogeneity but with policy neutral implications. This happens with a non-degenerate distribution of shocks for which $\Theta(1+\beta)=1$. For instance, when $\varepsilon+\beta \delta=1+\beta$ for all $(\varepsilon, \delta) \in \Xi$.

Next, we consider a case with only shocks to preferences for late consumption. In this case $\Theta=\mathbb{E}\{1 /(1+\beta \delta)\}$ and because $1 /(1+\beta \delta)$ is convex in $\delta$, Jensen's inequality implies that the ZLB does not bind. We find that optimal policy satisfies

$$
\pi=\beta(1+\beta) \mathbb{E}\left\{\frac{1}{1+\beta \delta}\right\} \text { and } \varphi \pi=\frac{\beta(1+\beta)}{\pi} \mathbb{E}\left\{\frac{\beta \delta}{1+\beta \delta}\right\},
$$

and because $\beta \delta /(1+\beta \delta)$ is concave in $\delta$, it follows from Jensen's inequality that $\pi>\beta$ and $\varphi \pi<\beta$. This means that optimal policy deviates from the Friedman rule in two dimensions. First, inflation is such that the real return on money falls short of the real natural interest rate. Second, the nominal interest rate is such that the real return on bonds exceeds the real natural interest rate. Relating to the work of Gomis-Porqueras and Waller (2017), we note that when the government is able to levy linear, age-contingent consumption taxes or subsidies, it can replicate the outcomes for the optimal monetary policy by means of fiscal policy. The reason is that age-contingent linear consumption taxes have similar effects on agents' choices for life-cycle consumption as inflation and the nominal interest rate.

Finally, we describe a case with only shocks to preferences for early consumption. Then $\Theta=\mathbb{E}\{\varepsilon /(\varepsilon+\beta)\}$ and because $\varepsilon /(\varepsilon+\beta)$ is concave in $\varepsilon$, Jensen's inequality implies that the ZLB constraint binds. Interestingly, the inflation rate satisfies $\pi>\beta$. The real return on money thus falls short of the real natural interest rate. Moreover, if the dispersion of shocks to preferences for early consumption is sufficiently large or the subjective discount factor is sufficiently high, we get a strictly positive rate of inflation as an optimal policy. Again relating to Gomis-Porqueras and Waller (2017), we can replicate the outcomes for the optimal monetary policy by means of an age-contingent linear consumption tax. Interestingly, using agecontingent consumption taxes, a policy maker can even replicate the optimal monetary policy when interest rates in the negative domain are feasible - e.g. when middle-aged agents can be forbidden to use cash as a savings vehicle (namely by taxing old-aged consumption heavily relative to middle-aged consumption).

\section{Quantitative analysis}

We are now ready to quantify the welfare, output, and consumption consequences of optimal policy and the endogenous ZLB across parameterized versions of the model. For this purpose, we start with a first-best economy. The first-best is characterized by a complete financial market structure, ensuring the most efficient distribution of resources. A complete financial market structure implies that preference shocks are observable and insurable, so newborn agents maximize:

$$
\mathcal{U}_{t}=\max _{h_{t},\left\{q_{\xi, t}^{m}, q_{\xi, t}^{o}\right\}_{\xi \in \Xi}}\left\{-h_{t}+\beta \mathbb{E}\left[\varepsilon u\left(q_{\xi, t}^{m}\right)\right]+\beta^{2} \mathbb{E}\left[\delta u\left(q_{\xi, t}^{o}\right)\right]\right\},
$$


s.t. $\quad \pi_{t+1}\left[\mathbb{E}\left[q_{\xi, t}^{m}\right]+\min \left\{\varphi_{t+1}, 1\right\} \pi_{t+2} \mathbb{E}\left[q_{\xi, t}^{o}\right]+\tau_{t+1}\right] \leq h_{t}$.

This means, the state-contingent budget constraint only needs to hold in expectation. It is straightforward to show that the optimization problem at (24) and (25) implies:

$$
h_{t}=\beta(1+\beta)+\pi_{t+1} \tau_{t+1}, \quad q_{\xi, t}^{m}=\varepsilon \beta / \pi_{t+1}, \quad \text { and } \quad q_{\xi, t}^{o}=\delta \beta^{2} /\left[\min \left\{\varphi_{t+1}, 1\right\} \pi_{t+1} \pi_{t+2}\right] .
$$

In turn, the first-best allocations at (26) yield the Friedman rule $(\pi=\beta$ and $\varphi=1)$ as the optimal monetary policy, $h=2$ as the optimal aggregate output, and $\tau=[2-\beta(1+\beta)] / \beta$ as the optimal lump-sum tax.

The questions that we would like to address in our quantitative analysis are threefold: (i) How does an economy with preference heterogeneity and incomplete markets compare to a first-best economy? (ii) How large are quantitative welfare losses when policy would simply adhere to the Friedman rule? (iii) What are the welfare losses from being unable to let interest rates take values in the negative domain?

\subsection{Parametrization}

To parameterize the model, we set the length of a period to 20 years. To obtain economically meaningful results, we choose $\beta=1 /(1.02)^{20} \approx 0.6730$ so that the real natural rate of interest equals $2 \%$ per annum. We assume that $\varepsilon$ and $\delta$ are drawn from independent log-normal distributions with standard deviations $\sigma_{\varepsilon}$ and $\sigma_{\delta}$, respectively. The first-best levels of early and late consumption are then log-normally distributed with mean one, and (relative) standard deviations of $\sigma_{\varepsilon}$ and $\sigma_{\delta}$. Hence, $\sigma_{\varepsilon}$ and $\sigma_{\delta}$ have intuitive economic interpretations. Moreover, choosing log-normal distributions for our preference shocks has straightforward implications too for the heterogeneity in agents' desire to save: the functional form implies that our key definition from Section $3, \theta=\varepsilon /(\varepsilon+\beta \delta)$, follows a logit-normal distribution. Specifically, $\operatorname{logit}(\theta)$ is normally distributed with mean $\mu_{\varepsilon}-\mu_{\delta}-\log (\beta)$ and standard deviation $\sqrt{\varsigma_{\varepsilon}^{2}+\varsigma_{\delta}^{2}}$. The variables $\mu_{x}=-\log \left(1+\sigma_{x}^{2}\right) / 2$ and $\varsigma_{x}^{2}=$ $\log \left(1+\sigma_{x}^{2}\right)$ are the mean and variance of $\log (x)$, respectively, with $x \in\{\varepsilon, \delta\}$.

The quantitative results from our parameterized model are presented in Figs. 1-13. In these figures, we primarily study the consequences of varying the heterogeneity of preferences, $\sigma_{\varepsilon}$ and $\sigma_{\delta}$, on optimal policy design and macroeconomic outcomes. For this purpose, we let the standard deviations of preference shocks vary between zero and one. ${ }^{10}$

\subsection{Optimal policy}

Figure 1 illustrates the behavior of the sufficient statistic $\Theta$, which is the average consumption quote of the middle-aged. The plot in Fig. 1 re-emphasizes the point that when the spread in late consumption shocks is small enough, even a very low standard deviation in early-consumption shocks induces ZLB to bind. This prevails when $\Theta(1+\beta)$ is greater than 1 or equivalently, $\Theta$ is greater than $1 /(1+\beta) \approx 0.5977$.

Figures $2 \mathrm{a}$ and $\mathrm{b}$ present the implications of preference heterogeneity on the optimal policy design with respect inflation and nominal interest rates. Figure $2 \mathrm{a}$ shows that the heterogeneity in both early and late consumption shocks cause deviations of optimal inflation from the Friedman rule, $\pi=\beta$ and $\varphi=1$, which requires a deflation of approximately $1.96 \%$ per annum. However, the quantitative policy effects of preference heterogeneity resulting from the spreads in $\varepsilon$ and $\delta$ are substantially different from each other. For example, while keeping $\sigma_{\varepsilon}=0$ and setting $\sigma_{\delta}=1$ implies a $+0.5 \%$-point change from the Friedman rule as the optimal inflation policy, setting $\sigma_{\varepsilon}=1$ and $\sigma_{\delta}=0$ results in an optimal deviation of the inflation rate from the Friedman-rule by only $+0.3 \%$-points. Intuitively, this is because at the ZLB, high inflation discourages both early and late consumption. Ideally, a policymaker promotes early consumption and discourages late consumption when the spread in $\varepsilon$ dominates the spread in $\delta$. When ZLB is binding, it is impossible to stimulate early consumption and discourage late consumption simultaneously. Because of compounding, inflation affects late consumption more than early consumption, and thus it becomes optimal to set the inflation rate higher than the Friedman rule. But, only a slight deviation results from the constrained optimum in order to also take into account the negative effects of inflation on early consumption.

Figure 2b reveals that when $\sigma_{\delta}$ is small, the ZLB binds for a wide range of $\sigma_{\varepsilon}$ values. This range shrinks as $\sigma_{\delta}$ goes up. In Figure $2 \mathrm{~b}$ we observe that when $\sigma_{\varepsilon}$ is small, since the economy moves away from ZLB, an optimal annual nominal interest rate as high as $2 \%$ can be attained.

As a comparison, Fig. $3 \mathrm{a}$ and $\mathrm{b}$ present the implications of preference heterogeneity on optimal policy absent a ZLB on nominal rates, i.e. in an environment in which households are forbidden to save for old-aged consumption by means of holding money. It demonstrates that when the spread in early consumption preference shocks is large relative to discount factor shocks, a policy maker wants to shift resources towards early consumption. The policy maker achieves this by reducing inflation relative to the Friedman rule to promote early consumption. In order to undo the strong compounding effect of

\footnotetext{
${ }^{10}$ The upper bound of one is motivated by the fact that numerically we approximate a continuous log-normal distribution with a discrete distribution. With high standard deviations, this approximation yields significant differences between the theoretical moments of a log-normal distribution and the actual moments of the distribution we feed to the model. This makes it difficult to connect our numerical results with the properties of a log-normal distribution.
} 
low inflation that would shift resources towards late consumption, nominal rates are moved into the negative territory and take values as low as $-3 \%$.

\subsection{Welfare effects}

We then move on and explore the effects of preference heterogeneity on aggregate welfare. First, Fig. 4 quantifies the welfare effects of not being able to implement first-best allocations in an environment where policy is set optimally and is constrained by the ZLB. Since utility is linear in labor effort and in equilibrium labor effort is equal to output produced, we express welfare effects as a percentage of the first-best output. We observe that the welfare losses resulting from incomplete markets are substantial when preference heterogeneity arises in our framework. With heterogeneity in both early and late consumption preferences, losses close to $22.5 \%$ of first-best output prevail when the (relative) standard deviation of first-best early and late consumption are both equal to one.

Figure 5a quantifies steady state welfare losses that arise when instead of being set optimally, policy adheres to the Friedman rule. In the absence of heterogeneity, i.e. when $\sigma_{\varepsilon}=\sigma_{\delta}=0$, the Friedman rule is optimal, which we take as a special-case corner. In comparison to this special-case, implementing the Friedman rule at higher levels of preference heterogeneity results in welfare losses when heterogeneity either in early or late consumption preferences is present. These losses are especially high when heterogeneity in late consumption preferences dominate, in which case the ZLB constraint is slack. The welfare loss from sub-optimal Friedman rule implementation could be as high as $1 \%$ of first-best output when $\sigma_{\delta}=1$.

Because it matters for optimal policy how an economy starts out, simply comparing steady state welfare levels might be misleading. Therefore, in Fig. 5b we consider what happens to an economy that starts with optimal policy but reverts back to the Friedman rule in period 1 . That means, $\pi_{t>1}=\beta$ and $\varphi_{t \geq 1}=1$. ${ }^{11}$ With allocations in period 0 and 1 being unaffected by such a policy change, we discount welfare losses back to period 2 and then express them as a percentage of the present value of current and future first-best output. Compared to Fig. 5a, we see that equivalent effects arise for such a policy experiment.

In Fig. 6a we evaluate the steady state welfare losses borne by the ZLB. Specifically, we conduct a counterfactual analysis, in which we allow for negative interest rates and compare the resulting welfare against the welfare in our baseline model. This analysis shows that allowing for negative interest rates on nominal bonds implies welfare gains that are as high as $1.5 \%$ of the first-best output. Again, besides simply comparing steady state welfare levels, Fig. 6b considers what happens when we revert to standard optimal policy in an economy that starts with optimal negative interest rates. Compared to Fig. 6a, we see that equivalent effects arise for such a policy experiment.

Finally, we also report relative welfare changes induced by implementing optimal policy rules instead of the Friedman rule. When the relative standard deviation of first-best early consumption equals one (as a benchmark case), the optimal policy increases steady state welfare by $0.6 \%$ of the first-best level of welfare. However, when the relative standard deviation of first-best late consumption equals one, the optimal policy increases steady state welfare by $1.2 \%$ of first-best level of welfare - a larger quantitative effect caused by a non-binding ZLB. Allowing for negative interest rates stimulates the aggregate welfare by $1.9 \%$ of first-best welfare when the relative standard deviation of first-best early consumption levels equals one.

\subsection{Output and taxation effects}

Figure 7a shows the effect on output of being unable to implement first-best allocations. We see that only when the ZLB binds, output in an optimal policy regime changes relative to that in a first-best economy. Output losses of not-being able to implement negative interest rates are as large as $4 \%$ when $\sigma_{\varepsilon}=1$ and $\sigma_{\delta}=0$. Intuitively, these output losses are due to the fact that at the ZLB, reducing late consumption comes at the cost of reducing early consumption.

Figure $7 \mathrm{~b}$ shows the effects on output when instead of being set optimally, policy adheres to the Friedman rule. When the ZLB is slack, implementing the Friedman rule reduces output. With a binding ZLB constraint, implementing the Friedman rule improves output but, as established earlier, at the cost of steady state welfare.

Figure 8a shows the effect on taxation of being unable to implement first-best allocations. Similarly, Fig. 8b shows the effects on taxation when instead of being set optimally, policy adheres to the Friedman rule. The figures are in line with our results at Corollary 3 and show that overall, taxation reduces as a result of the implementation of the optimal policy. This points towards the fact that the Friedman rule, which is the optimal policy when first-best allocations can be implemented, may result in too much taxation when financial markets are incomplete.

Our numerical results also indicate that the taxation effect is economically significant: When the relative standard deviation of first-best early consumption equals one, the difference between optimal taxation and taxation at the Friedman rule is approximately $15 \%$ of first-best output and when the relative standard deviation of first-best late consumption equals one, the difference between optimal taxation and taxation at the Friedman rule is approximately $2.5 \%$ of first-best output. The asymmetry here is caused by the ZLB constraint, which binds in the former case but is slack in the latter.

\footnotetext{
11 This implies that reverting to the Friedman rule does not affect any of the incumbent middle-aged and old-aged households. Moreover, the policy change is announced before the newborn young households make their decisions. Summarizing, nobody is surprised by the policy change.
} 


\subsection{Consumption effects}

We also decompose the output effects as consequences on early and late consumption. Figures 9a and b show that when the ZLB does not bind, aggregate early and late consumption are equal to their first-best levels. Since stimulating early consumption and discouraging late consumption simultaneously is difficult with an endogenous ZLB, we see that when early consumption shocks dominate and thus the ZLB binds, early consumption reduces and late consumption increases relative to first-best levels. With $\sigma_{\varepsilon}=1$ and $\sigma_{\delta}=0$, these effects are large; early consumption reduces by almost $20 \%$ while late consumption increases by more than $12 \%$ relative to first-best.

Figures $9 \mathrm{~b}$ and 10b show that when implementing the Friedman rule instead of optimal policy, early consumption always increases. When reverting to the Friedman rule, late consumption increases if the ZLB binds but reduces if the ZLB is slack.

Finally, in Figs. 11-13 we study the distributional effects of policy on consumption. We do so for two different cases; $\left\{\sigma_{\varepsilon}, \sigma_{\delta}\right\}=\{0.5,1\}$ and $\left\{\sigma_{\varepsilon}, \sigma_{\delta}\right\}=\{1,0.5\}$. For the first case, the ZLB does not bind, optimal inflation is $-1.68 \%$, and the optimal nominal rate is $1.0 \%$. For the second case, the ZLB binds and optimal inflation is $-1.77 \%$. In the counterfactual of the ZLB absence, in the latter case optimal inflation would be $-2.59 \%$ and the optimal nominal rate $-2.1 \%$. Figure $11 \mathrm{a}$ and $\mathrm{b}$ show how $\theta$, i.e. middle aged agents' consumption quote, is distributed.

For the first case, Fig. 12a and b show how optimal policy shifts the distribution of early consumption to the left and the distribution of late consumption to the right, when compared to consumption distributions under the Friedman rule.

For the second case, Fig. 13a and b show how optimal policy shifts the distribution of both early consumption and late consumption to the left when compared to consumption distributions under the Friedman rule. Absent a ZLB in the second case, optimal policy shifts the distribution of late consumption further to the left but the distribution of early consumption back to the right.

These distributional consequences highlight that the monetary policy could be effective in improving allocation efficiency in a society. In comparison to the first-best allocations that we also depict in Figs. 12 and 13 , we make two additional remarks: There is a clear distributional effect of allowing negative interest rates in moving the allocations towards the firstbest. However, these graphs also imply that the optimal monetary policy - despite being effective - does not cover the full distance in pushing the allocations to their first-best levels, pointing out the need for fiscal policy to work in tandem with monetary policy if the objective is to achieve first-best allocations.

\subsection{Calibration}

We conclude the quantitative analysis by calibrating our model based on the life-cycle features of the US data. Regardless of structural assumptions about the distribution of the preference shocks, our model produces a closed form and invertible map between the sufficient statistic $\Theta$ and a model-implied moment that we can link to the data.

For a random variable $X$, let $\mathbb{E}\{X\}$ denote the expectation, $\mathbb{S D}\{X\}$ the standard deviation, and $\mathbb{R} \mathbb{S D}\{X\} \equiv \mathbb{S D}\{X\} / \mathbb{E}\{X\}$ the relative standard deviation. From Eq. (8), we can calculate RSDs for middle-aged and old consumption

$$
\mathbb{R} \mathbb{D}\left\{q_{\xi, t}^{m}\right\}=\frac{\mathbb{S D}\{\theta\}}{\mathbb{E}\{\theta\}} \text { and } \mathbb{R} \mathbb{S D}\left\{q_{\xi, t}^{o}\right\}=\frac{\mathbb{S D}\{1-\theta\}}{\mathbb{E}\{1-\theta\}},
$$

which are independent of inflation and the nominal interest rate. Furthermore, $\Theta=\mathbb{E}\{\theta\}$ and $\mathbb{S D}\{\theta\}=\mathbb{S D}\{1-\theta\}$. Assuming that preferences are time-invariant, we can therefore calculate the sufficient statistic $\Theta$ from the model's data generating process by means of the following equation

$$
\Theta=\frac{\mathbb{R S D}\left\{q_{\xi, t}^{o}\right\}}{\mathbb{R S D}\left\{q_{\xi, t}^{o}\right\}+\mathbb{R} \mathbb{D}\left\{q_{\xi, s}^{m}\right\}} \forall t, s .
$$

Using the equation above, we calibrate the sufficient statistic $\Theta$ using the US data on life-cycle expenditure from Aguiar and Hurst (2013). This data is based on all Consumer Expenditure Survey (CEX) waves from 1980 through 2003 , from which the authors extract a panel of 53,412 households for which the head is between the ages of 25 and 75 . $^{12}$ We calculate $q_{\xi, t}^{m}$ and $q_{\xi, t}^{o}$ as real expenditure on core, non-durable consumption goods. ${ }^{13}$ We define the young as everybody aged 25 up to and including 44, the middle aged as everybody aged 45 up to and including 64, and the old as everybody aged 65 or older. We choose this classification to have time periods of 20 years, just as in the parametrization specified in Section 4.1. For each calendar year in the sample, we then calculate the mean and standard deviation of consumption for the middle-aged and old. The results are shown in Fig. 14.

Based on Eq. (28), we then calculate $\Theta$ on a year-to-year basis by dividing the RSD of old-aged consumption by the sum of the RSD of middle-aged consumption and the RSD of old-aged consumption. The results are shown in Fig. 15. Panel Fig. 15a shows the development of the relative standard deviation of middle-aged and old-aged consumption. Panel Fig. 15b shows the calculated value for $\Theta$ on a year-to-year basis. The average value for $\Theta$ equals approximately 0.51 . As

\footnotetext{
${ }^{12}$ The authors restrict attention to households that report positive consumption expenditures on six main categories and for which at least 10 years of data is available. The latter ensures the panel is at least somewhat balanced. Details are provided in Appendix A of Aguiar and Hurst (2013).

13 Aguiar and Hurst (2013) provide expenditure data expressed in year 2000 US Dollars.
} 
Table 1

Optimal policy and counterfactuals for $\Theta=0.51$. The optimal inflation rate and the optimal nominal rate are expressed in annualized percentages. All counterfactual welfare and output gains (losses) are expressed as a percentage of first-best output.

\begin{tabular}{|c|c|c|c|c|}
\hline Value for $\beta$ & 1 & $1 / 1.01^{20}$ & $1 / 1.02^{20}$ & $1 / 1.03^{20}$ \\
\hline Optimal Inflation & $0.11 \%$ & $-0.90 \%$ & $-1.74 \%$ & $-2.53 \%$ \\
\hline Optimal Nominal Rate & $0.34 \%$ & ZLB & ZLB & ZLB \\
\hline Inflation at Friedman Rule & $0 \%$ & $-0.99 \%$ & $-1.96 \%$ & $-2.91 \%$ \\
\hline Nominal Rate at Friedman Rule & $0 \%$ & $0 \%$ & $0 \%$ & $0 \%$ \\
\hline Welfare Loss at Friedman Rule & $0.026 \%$ & $0.048 \%$ & $0.36 \%$ & $1.19 \%$ \\
\hline Output Gain at Friedman Rule & $0.00 \%$ & $2.70 \%$ & $7.19 \%$ & $13.02 \%$ \\
\hline Optimal Inflation if no ZLB & $0.11 \%$ & $-1.35 \%$ & $-2.72 \%$ & $-4.02 \%$ \\
\hline Optimal Nominal Rate if no ZLB & $0.34 \%$ & $-1.12 \%$ & $-2.50 \%$ & $-3.81 \%$ \\
\hline Welfare Loss due to ZLB & - & $0.25 \%$ & $1.23 \%$ & $2.81 \%$ \\
\hline Output Loss due to ZLB & - & $1.94 \%$ & $3.67 \%$ & $4.74 \%$ \\
\hline
\end{tabular}

Fig. 15 demonstrates, the year-to-year development is relatively stable, except for a peak in 1988 and some volatility from 2000 till 2003. As Fig. 14 and further analysis demonstrate, these fluctuations are driven primarily by outliers in the data for old-age consumption, which result in high standard deviations.

In what follows, we use $\Theta=0.51$ to provide numerical results related to the analysis in the preceding subsections. Because we cannot calibrate $\beta$ from the model's data generating process, we provide results for three values for $\beta .{ }^{14}$ These are based on annualized rates of time preference of $0 \%, 1 \%, 2 \%$, and $3 \%$. Given previous work in literature, we consider the rate of time preference of $2 \%$ as the most relevant one.

Table 1 shows the results for optimal policy and some associated counterfactuals. We see that for our preferred value for $\beta$, the ZLB is binding and the optimal policy implements a slight deviation from the Friedman rule. The welfare loss associated with implementing the Friedman rule instead of the optimal policy is moderate. Depending on the rate of time preference, this loss ranges from $0.026 \%$ to $1.19 \%$ of first-best output. Implementing the Friedman rule does however result in an output gain, and the size of this gain varies significantly with the rate of time preference. For our preferred value for $\beta$, implementing the Friedman rule rather than the optimal policy increases output by $7.19 \%$ of first-best output.

We also study the effects of the binding ZLB constraint. If the government could implement interest rates in the negative domain, for instance by forbidding the use of cash as a savings vehicle for the middle-aged, the optimal nominal interest rate would be $-2.50 \%$ and the optimal inflation rate $-2.72 \%$ for our preferred rate of time preference. Doing so would result in a welfare gain of $1.23 \%$ of first-best output, as well as an output increase of $3.67 \%$ of first-best output. In this sense, the welfare and output loss associated with the binding ZLB constraint is sizable. A similar result holds true for the other rates of time preference for which the ZLB constraint binds.

For our preferred value for $\beta$, we also illustrate graphically the steady state welfare and output effects of implementing other, non-optimal policies. The results are shown in Fig. 16, which demonstrates that the effects of implementing nonoptimal policies can be very sizable. We do however think that these results should be taken with a grain of salt. This is because the length of a time period in our model is 20 years. Due to compounding, annualized inflation and interest rates that seem close to the optimal policy therefore have big implications in the calibrated model. As Fig. 16 demonstrates, an environment with interest rates at the ZLB and inflation around $2 \%$ already results in a welfare loss close to $40 \%$ of first-best output and an output gain of $50 \%$ of first-best output.

Finally, we compare consumption over the life-cycle in our calibrated model to the data. For this purpose, we look at the ratio of aggregate middle-aged consumption over aggregate old-aged consumption. ${ }^{15}$ In the steady state equilibrium of our model, this ratio satisfies

$$
\frac{\mathbb{E}\left\{c_{\xi, t}^{m}\right\}}{\mathbb{E}\left\{c_{\xi, t}^{o}\right\}}=\frac{\varphi \pi \Theta}{1-\Theta},
$$

and is dependent on the sufficient statistic $\Theta$ as well as policy. To be specific, the ratio is inversely related to the real rate of interest earned by bonds. Table 2 reports the ratio $\mathbb{E}\left\{c_{\xi, t}^{m}\right\} / \mathbb{E}\left\{c_{\xi, t}^{o}\right\}$ for the optimal policy and the calibrated value for $\Theta$.

As a comparison, we also calculate the ratio of middle-aged over old-aged consumption in the data. Figure 17 shows the results. Apart from a peak in 1980, the ratio is pretty stable. Excluding the year 1980, we find an average ratio of 1.14 , which

\footnotetext{
${ }^{14} \beta$ is unidentified even if we assume log-normally distributed preference shocks. While $\theta=\varepsilon /(\varepsilon+\beta \delta)$ can be identified easily, identifying $\beta$ requires knowledge of the underlying distributions for $\varepsilon$ and $\delta$. In turn, different distributions for $\varepsilon$ and $\delta$ can produce the same data generating process. Furthermore, the fact that $q^{m}=\beta(1+\beta) \theta / \pi$ and $q^{m}=\beta(1+\beta)(1-\theta) /\left(\varphi \pi^{2}\right)$ does not generate a meaningful identification for $\beta$ as we have normalized labor productivity in the GM to one. If labor productivity would be $A$, we would obtain $q^{m}=A \beta(1+\beta) \theta / \pi$ and $q^{o}=A \beta(1+\beta)(1-\theta) /\left(\varphi \pi^{2}\right)$ so we cannot distinguish between $A$ and $\beta(1+\beta)$.

15 Looking at the levels for middle-aged and old consumption is uninteresting, as they are proportional to labor productivity - doubling labor productivity by the young will double middle-aged and old-aged consumption.
} 
Table 2

The model implied ratio $\mathbb{E}\left\{c_{\xi, t}^{m}\right\} / \mathbb{E}\left\{c_{\xi, t}^{m}\right\}$ given the optimal policies for $\Theta=0.51$.

\begin{tabular}{lllll}
\hline Value for $\beta$ & 1 & $1 / 1.01^{20}$ & $1 / 1.02^{20}$ & $1 / 1.03^{20}$ \\
\hline $\mathbb{E}\left\{c_{\xi, t}^{m}\right\} / \mathbb{E}\left\{c_{\xi, t}^{o}\right\}$ given opt. policy & 1 & 0.87 & 0.74 & 0.63 \\
\hline
\end{tabular}

is significantly higher than what we find for the optimal policies. This suggest that from an optimal policy perspective, the real interest rate on bonds in the US is too low. We also note that given the calibrated value for $\Theta$, our model replicated the US ratio of 1.14 for an annualized real interest rate of $-0.44 \%$. This value is rather low given that our sample runs from 1980 till 2003. At the same time, it is in line with the post financial crisis appearance of negative real interest rates.

\section{Real investment and private assets}

In our benchmark model households do not have the option to accumulate wealth through private means. In order to check the sensitivity of our qualitative findings to this benchmark specification, in this section, we introduce a private asset into the model and allow that asset to compete with nominal bonds. We continue to assume the same structure as before and also that in the GM money is the only medium of exchange. However, different from what we introduced in Section 3 , households have access to a long-run investment technology which serves as an alternative form of savings instrument in addition to nominal bonds. We are interested in understanding whether the optimal policy mix that we derived in Section 3 , remains qualitatively valid when households face an alternative (real) investment option.

Formally, we assume that in any time period $t$, all young households have access to a decreasing returns to scale investment technology during the GM. Specifically, for each $k_{t}$ units of goods invested in GM $t$, the technology returns

$$
y_{t+2}=\frac{A k_{t}^{1-\alpha}}{1-\alpha}, \quad \alpha \in(0,1)
$$

units of goods in the GM of period $t+2$. Furthermore, in the FM of period $t+1$, a household can issue claims against the future output of its investment technology. Other households and also the government, can purchase these claims. When the government engages in asset purchases, it leads to the emergence of asset-backed money. That means, in the FM of period $t+1$ the government can buy privately issued financial claims by printing money. By selling off these claims in period $t+2$, the injected money can be withdrawn and the government may earn seignorage revenues. Importantly, the ability of the government to issue asset-backed money implies full control over inflation and nominal interest rates.

\subsection{Optimizing behavior and equilibrium}

We let $\psi_{t}$ denote the FM $t$ price of a claim against one unit of good to be delivered in the GM of period $t+1-$ measured in terms of the GM goods in period $t$. A no-arbitrage condition, equating the real return on bonds to that on claims against investment, implies $\psi_{t}=\varphi_{t} \pi_{t+1}$. The lifetime utility maximization problem of a household then becomes:

$$
\begin{aligned}
& \mathcal{U}_{t}=\max _{h_{t}, k_{t},\left\{q_{\xi, t}^{m}, q_{\xi, t}^{o}\right\}_{\xi \in \Xi}}\left\{-h_{t}-k_{t}+\beta \mathbb{E}\left[\varepsilon u\left(q_{\xi, t}^{m}\right)\right]+\beta^{2} \mathbb{E}\left[\delta u\left(q_{\xi, t}^{o}\right)\right]\right\}, \\
& \text { s.t. } \quad \pi_{t+1}\left[q_{\xi, t}^{m}+\varphi_{t+1} \pi_{t+2} q_{\xi, t}^{o}+\tau_{t+1}\right] \leq h_{t}+\frac{\varphi_{t+1} \pi_{t+1} \pi_{t+2} A k_{t}^{1-\alpha}}{1-\alpha}, \forall \xi \in \Xi . \\
& \quad h_{t} \geq 0, \quad \text { and } \quad k_{t} \geq 0 .
\end{aligned}
$$

Based on the extended optimization problem at (31)-(33) we first establish the following lemma, which characterizes the equilibrium.

Lemma 2. (i)Aggregate supply and demand in any time period $t$ are characterized by:

$$
\begin{aligned}
& Q_{t}^{s}=\beta(1+\beta)+\pi_{t+1} \tau_{t+1}+A^{1 / \alpha}\left(\left[\varphi_{t-1} \pi_{t-1} \pi_{t}\right]^{\frac{1-\alpha}{\alpha}}-\left[\varphi_{t+1} \pi_{t+1} \pi_{t+2}\right]^{\frac{1}{\alpha}}\right) /(1-\alpha), \\
& Q_{t}^{d}=\Theta \beta(1+\beta) / \pi_{t}+\beta(1+\beta)(1-\Theta) /\left(\varphi_{t-1} \pi_{t-1} \pi_{t}\right) .
\end{aligned}
$$

(ii) The amount of labor devoted to acquiring cash and investment goods are given by:

$$
h_{t}=\beta(1+\beta)+\pi_{t+1} \tau_{t+1}-\left[A \varphi_{t+1} \pi_{t+1} \pi_{t+2}\right]^{1 / \alpha} /(1-\alpha) \quad \text { and } \quad k_{t}=\left[A \varphi_{t+1} \pi_{t+1} \pi_{t+2}\right]^{1 / \alpha} .
$$

(iii) Finally, in a steady state equilibrium the following condition ensures that the labor-supply satisfies $h>0$ :

$$
\frac{A^{\frac{1}{\alpha}}\left(\varphi \pi^{2}\right)^{\frac{1-\alpha}{\alpha}}}{1-\alpha}<\frac{\beta(1+\beta)(\varphi \pi \Theta+1-\Theta)}{\varphi \pi^{2}} .
$$


We would like to first note that, in order to keep the analysis comparable to that of Section 3 , we restrict our attention to cases in which $h>0$ holds, because otherwise there is no inter-generational monetary exchange. Lemma 2 shows that $h>0$ is the case if the productivity of the long-run investment technology is sufficiently low. The intuition for this property is straightforward: when the long-run technology is too productive, agents can finance consumption needs in both periods using only the long-run technology. In addition to this property, Lemma 2 also characterizes the equilibrium quantities produced (and demanded), which, different than the benchmark specification, contain terms related to labor- and capitalbased output.

\subsection{Optimal policy}

A government with perfect commitment maximizes

$$
\mathcal{W}_{t}=\sum_{s=t}^{\infty} \beta^{s-t}\left[\mathbb{E}\left\{\varepsilon u\left(q_{\xi, s-1}^{m}\right)\right\}+\mathbb{E}\left\{\delta u\left(q_{\xi, s-2}^{o}\right)\right\}-h_{s}-k_{s}\right]
$$

by choosing a sequence $\left\{\varphi_{s}, \pi_{s+1}\right\}_{s=t+1}^{\infty}$ s.t. $\varphi_{s} \leq 1$, and taking as given $\left\{\varphi_{s}, \pi_{s+1}\right\}_{s=0}^{s=t}$ and $\left\{k_{s}\right\}_{s=0}^{s=t-1}$. Using our logarithmic utility specification, the welfare function at (38) can be written as:

$$
\mathcal{W}_{t}=\sum_{s=t}^{\infty} \beta^{s-t}\left\{\begin{array}{l}
\Delta-\log \left(\pi_{s}\right)-\frac{\Theta \beta(1+\beta)}{\pi_{s}}-\log \left(\varphi_{s-1} \pi_{s-1} \pi_{s}\right)-\frac{(1-\Theta) \beta(1+\beta)}{\varphi_{s-1} \pi_{s-1} \pi_{s}} \\
+A \frac{1}{\alpha} \frac{\left[\varphi_{s-1} \pi_{s-1} \pi_{s}\right]^{\frac{1-\alpha}{\alpha}}-(1-\alpha)\left[\varphi_{s+1} \pi_{s+1} \pi_{s+2}\right]^{\frac{1}{\alpha}}}{1-\alpha}
\end{array}\right\},
$$

with $\Delta$ given by (15). We characterize the government's optimal policy mix in the following proposition.

Proposition 2. The optimal policy mix in a steady state equilibrium satisfies:

$$
\begin{aligned}
& \varphi= \begin{cases}1 & \text { if } \Theta(1+\beta)<1 \\
\frac{1-\Theta}{\Theta^{2} \beta(1+\beta)}+o_{\varphi} & \text { if } \Theta(1+\beta) \geq 1\end{cases} \\
& \pi=\left\{\begin{array}{ll}
(1+\beta) \frac{\Theta \beta+\sqrt{\beta} \sqrt{\beta \Theta^{2}+4(2+\beta)(1-\Theta)}}{2(2+\beta)}-o_{\pi} & \text { if } \Theta(1+\beta) \leq 1 \\
\Theta \beta(1+\beta) & \text { if } \Theta(1+\beta)>1
\end{array} .\right.
\end{aligned}
$$

When the ZLB constraint does not bind, the difference between the optimal price of bonds with and without an investment technology is given by $o_{\varphi}$. This object is a positive solution of the following equation

$$
o_{\varphi}[\Theta \beta(1+\beta)]^{2}=\frac{\left\{A \beta(1+\beta)\left[1-\Theta+o_{\varphi} \Theta^{2} \beta(1+\beta)\right]\right\}^{\frac{1}{\alpha}}}{\alpha}\left[1-(1+\beta) \frac{1-\Theta+o_{\varphi} \Theta^{2} \beta(1+\beta)}{\beta}\right] .
$$

When the ZLB constraint binds, the difference between optimal inflation with and without an investment technology is given by $o_{\pi}$. This object is the unique positive solution of the following equation

$$
0=o_{\pi}\left[o_{\pi}(2+\beta)-2 \mathrm{Y}(2+\beta)+\Theta \beta(1+\beta)\right]-\left[A\left(\mathrm{Y}-o_{\pi}\right)^{2}\right]^{\frac{1}{\alpha}}\left[1-\left(\mathrm{Y}-o_{\pi}\right)^{2} / \beta^{2}\right](1+\beta) / \alpha,
$$

where $\Upsilon=(1+\beta)\left[\Theta \beta+\sqrt{\beta} \sqrt{\beta \Theta^{2}+4(2+\beta)(1-\Theta)}\right] /[4+2 \beta]$.

With $A$ sufficiently large, $o_{\varphi}$ may not be determined uniquely and additional second-order conditions need to be considered. In what follows, we consider $A$ as sufficiently small so that $o_{\varphi}$ is pinned down uniquely by Eq. (42). With respect to the qualitative properties that we discuss next, this simplification has been made without loss of generality.

Proposition 2 highlights an important robustness of our optimal policy characterization. Specifically, the threshold that determines the cut-off point for a ZLB constraint remains the same as in Section 3. To review from there, ceteris paribus, an increase in the heterogeneity of late consumption preferences lowers the likelihood of a binding ZLB, while increasing the heterogeneity of early consumption preferences raises the likelihood of a binding ZLB. Qualitatively, optimal policy also looks similar to what we characterized in Section 3, except either the optimal interest rate on nominal bonds (when the ZLB is slack) or the optimal inflation rate (when the ZLB binds) exhibits a distortionary wedge due to the presence of real asset formation by households. It also remains true as in Section 3 that $\pi \geq \beta$, with equality if and only if $\Theta(1+\beta)=1$, and $\varphi \leq 1$ with equality if and only if $\Theta(1+\beta) \leq 1$.

With respect to the distortionary wedges on inflation and bond pricing policies, we obtain important comparative statics with an intuitive interpretation. Specifically, $\lim _{A \rightarrow 0} o_{\varphi}=0$ and $\lim _{A \rightarrow 0} o_{\pi}=0$. Also, $\partial o_{\varphi} / \partial A>0$ and $\partial o_{\pi} / \partial A>0$. This means, the higher the productivity of private investment, the larger become the distortionary wedges associated with optimal policy. The reason is that real investment is affected by the real return earned by government bonds through a no arbitrage condition. Since first-best investment prevails when this real rate of return equals the natural real interest rate, the presence of a real investment technology pulls optimal policy towards the Friedman rule. 


\subsection{Qualitative illustration of optimal policy}

When there are no preference shocks or policy neutral shocks, such that $\Theta(1+\beta)=1$, we conclude as in Section 3 with the optimality of the Friedman rule $(\pi=\beta$ and $\varphi=1)$. Observing how investment enters the first-order conditions, we see that the first-best level of investment requires $\varphi \pi^{2}=\beta^{2}$. With no or policy-neutral idiosyncratic preference shocks, optimal levels of consumption are attained when $\pi=\beta$ and $\varphi=1$. Thus, the introduction of a real investment opportunity and private asset formation has no effect on the optimality of the Friedman rule in this particular case.

In a specification with shocks to only late consumption, which implies $\Theta(1+\beta)>1$, the ZLB is slack. Early consumption is determined by $\pi$ and late consumption by $\varphi \pi^{2}$. Because investment is determined by $\varphi \pi^{2}$, the investment technology only affects optimal nominal interest rates and not the optimal inflation rate. With $\Theta(1+\beta)>1$, optimal late consumption requires $\varphi \pi^{2}=\beta(1+\beta)(1-\Theta)<\beta^{2}$ while optimal investment requires $\varphi \pi^{2}=\beta^{2}$. Optimal policy balances these two conditions and therefore implies too little investment relative to the Friedman rule - which implements the first-best level of investment - and too much late consumption relative to the baseline model with an optimally chosen policy.

When there are shocks to early consumption only, which implies $\Theta(1+\beta)<1$, the ZLB constraint binds. Optimal aggregate consumption requires $\pi>\beta$ while optimal investment requires $\pi=\beta$. Optimal policy trades off these two. The investment technology therefore affects the inflation, and compared to the Friedman rule, the optimal inflation implies $\pi>\beta$ with too much investment relative to first-best and too little late consumption relative to the baseline model with an optimally chosen policy.

\section{Conclusion}

We studied preference heterogeneity and optimal monetary policy in a dynamic general equilibrium model of money with incomplete financial markets. Our benchmark theoretical model incorporates two-dimensional consumption preference heterogeneity: idiosyncratic shocks to current consumption and discount factors. Although we model preference shocks in a general way, the model is tractable to yield clean theoretical insights and quantifiable effects. We show that the shocks to current (early) consumption could cause an endogenous ZLB to bind - an effect that could get mitigated by discount factor heterogeneity. We characterize optimal policy and study the behavior of optimal inflation and nominal interest rates. The optimal policy, in general, deviates from the Friedman rule, but the motives for deviation are different depending on the type of preference heterogeneity. Our qualitative results are robust to allowing for alternative savings instruments.

The quantitative analysis based on the theoretical framework reveals that - when implemented optimally - policy can partially substitute for the lack of complete financial markets. However, the ZLB is a constraining factor. We conduct a counterfactual analysis to evaluate the macroeconomic effects of optimal negative interest rates. This counterfactual analysis shows that allowing for negative interest rates on nominal bonds can result in welfare gains that are estimated at $1.23 \%$ of first-best output in our calibrated version of the baseline model.

\section{Appendix A}

Figures

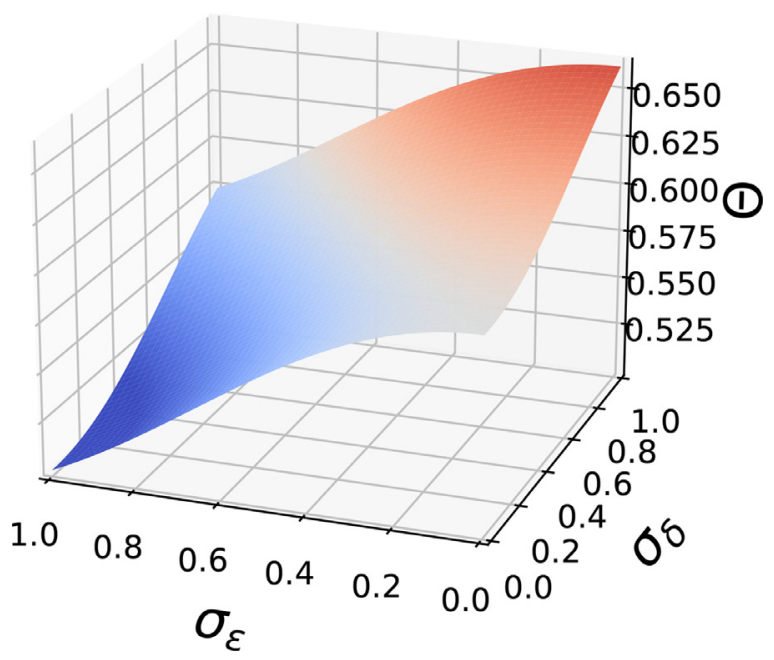

Fig. 1. Sufficient statistic $\Theta$ for log-normally distributed preference shocks. The colormap is normalized around $\Theta=1 /(1+\beta)$. 


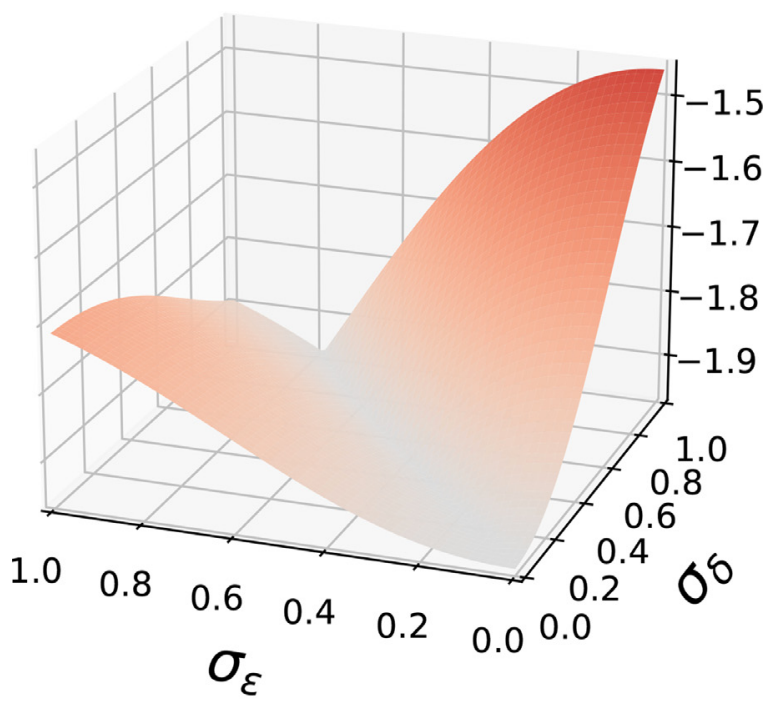

(a) Optimal inflation.

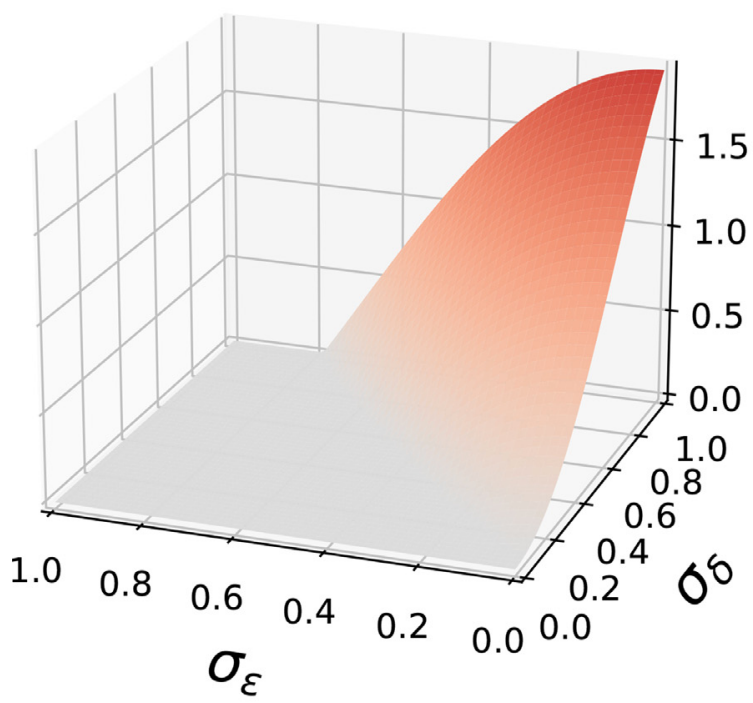

(b) Optimal nominal rate.

Fig. 2. Optimal policy with log-normal preference shocks and without a ZLB contraint. Inflation and nominal interest rates are expressed as annualized percentages. The colormap for inflation and nominal interest rates are normalized around the Friedman rule. 


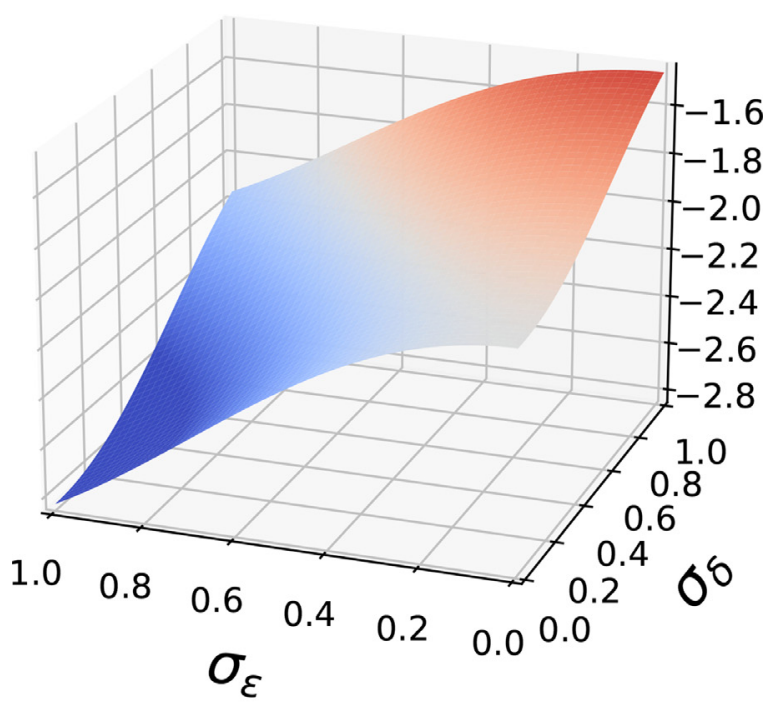

(a) Optimal inflation without a ZLB.

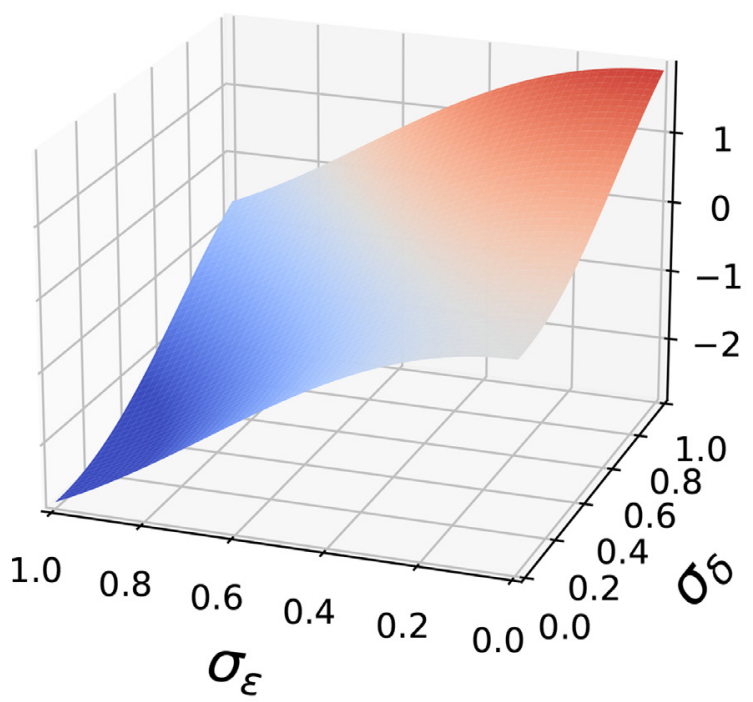

(b) Optimal interest rate without a ZLB.

Fig. 3. Optimal policy with log-normal preference shocks. Inflation and nominal interest rates are expressed as annualized percentages. The colormap for inflation and nominal interest rates are normalized around the Friedman rule. 


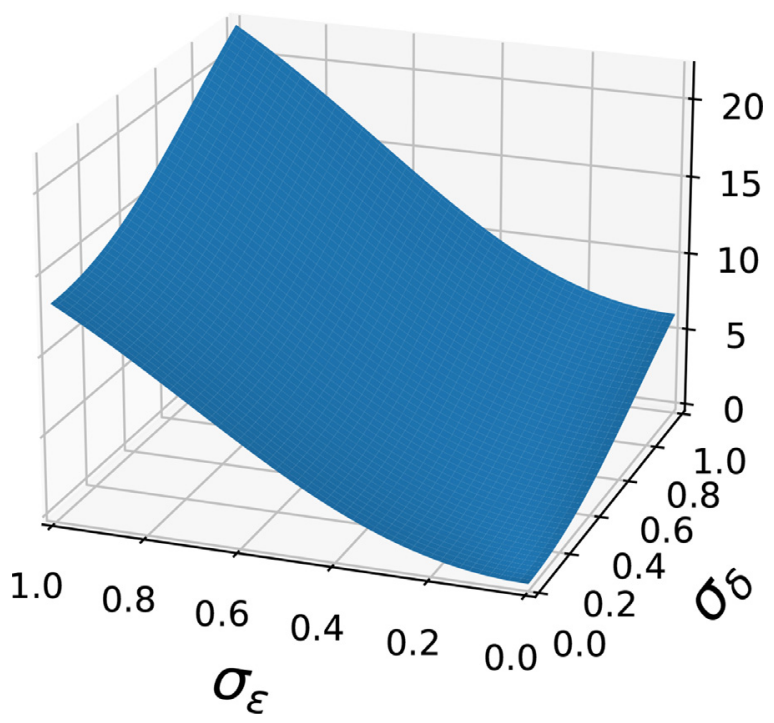

Fig. 4. Steady state welfare loss of not being able to implement first-best allocations, given log-normally distributed preferences shocks. The effect is expressed as a percentage of steady state output for first-best allocations. 


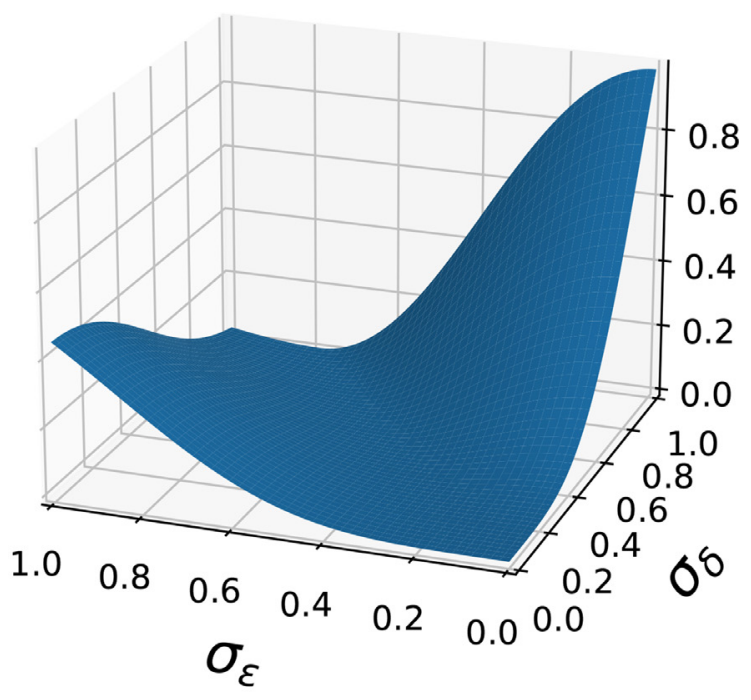

(a) Steady state welfare loss of Friedman rule.

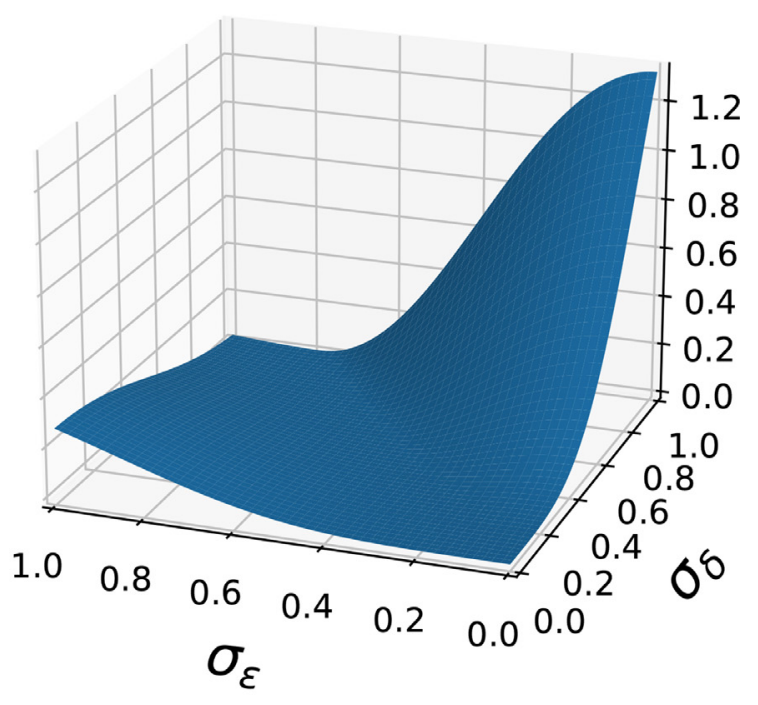

(b) Dynamic welfare loss of Friedman rule.

Fig. 5. Welfare losses of adhering to the Friedman rule, given log-normally distributed preferences shocks. All effects are expressed as a percentage of steady state output for first-best allocations. 


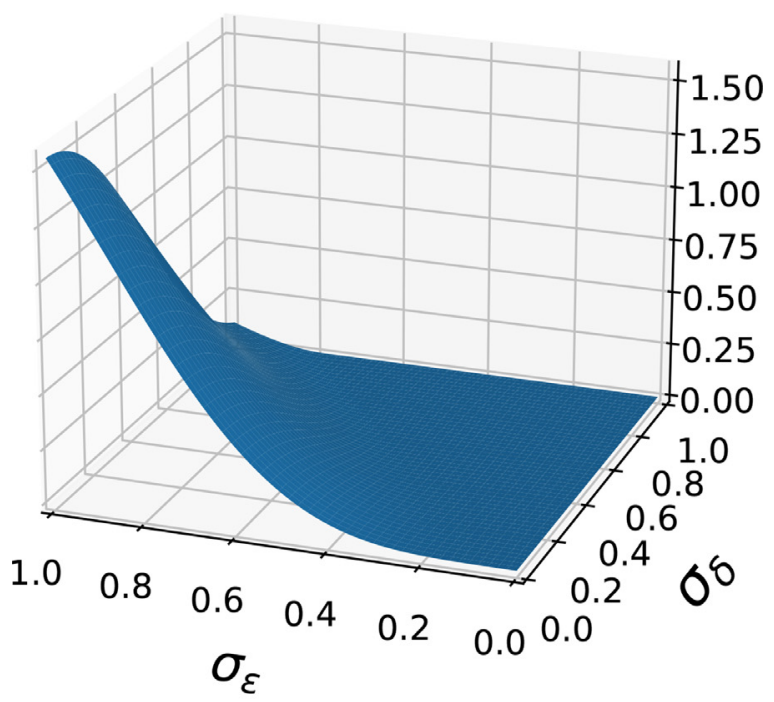

(a) Steady state welfare loss of ZLB.

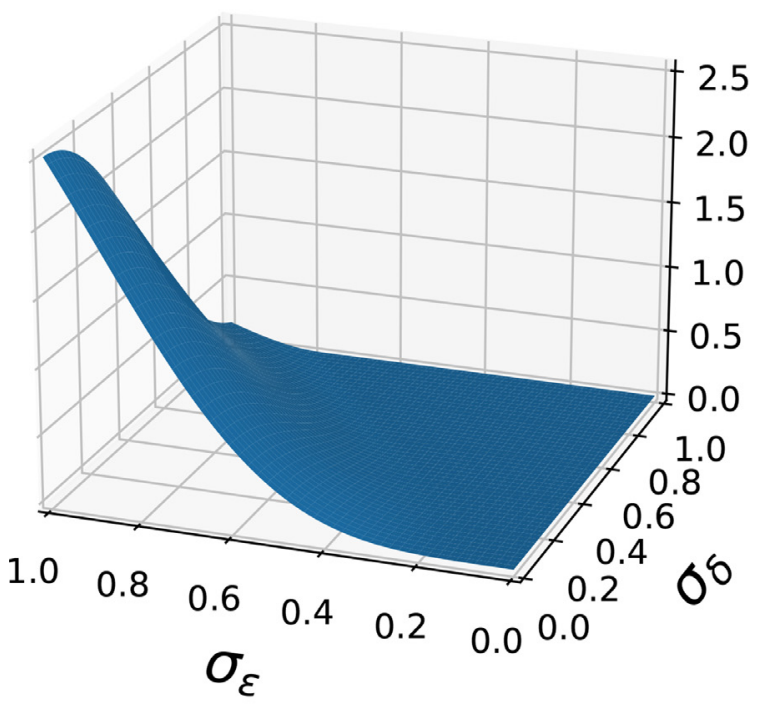

(b) Dynamic welfare loss of ZLB.

Fig. 6. Welfare losses due to binding ZLB constraint, given log-normally distributed preference shocks. All effects are expressed as a percentage of steady state output for first-best allocations. 


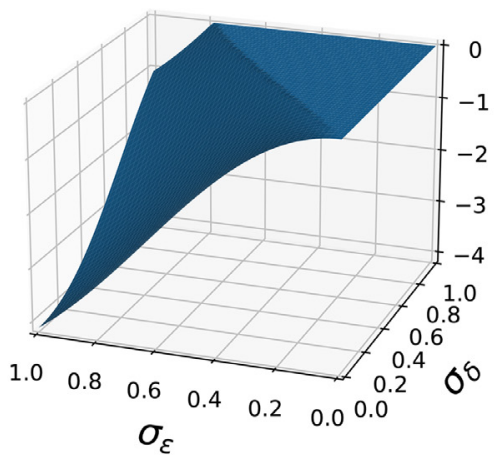

(a) Difference between output with optimal policy and first-best output.

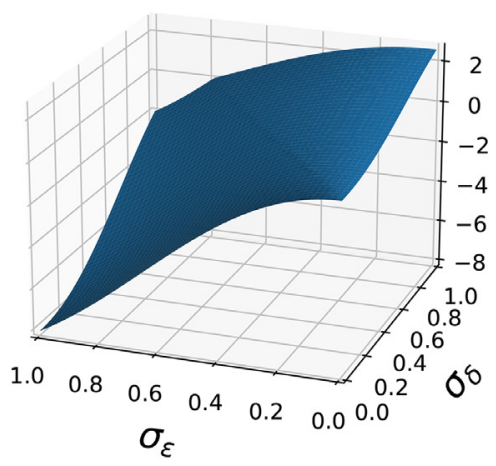

(b) Difference between output at the optimal policy and the Friedman rule.

Fig. 7. Output effects for log-normally distributed preferences shocks. All effects are expressed as a percentage of output for first-best allocations. 


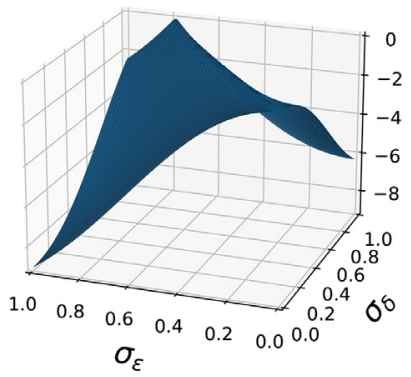

(a) Difference between taxation with optimal policy and taxation with first-best allocations.

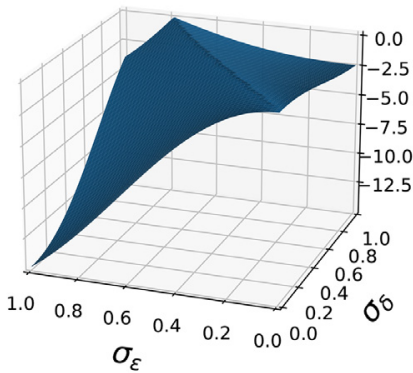

(b) Difference between taxation at the optimal policy and the Friedman rule.

Fig. 8. Tax effects for log-normally distributed preferences shocks. All effects are expressed as a percentage of output for first-best allocations.

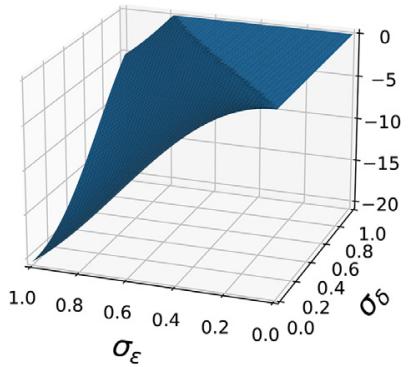

(a) Difference between early consumption with optimal policy and the first-best level of early consumption.

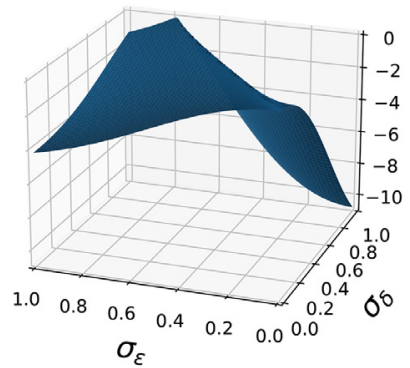

(b) Difference between early consumption at optimal policy and the Friedman rule.

Fig. 9. Aggregate early consumption effects for log-normally distributed preferences shocks. All effects are expressed as a percentage of first-best early consumption. 


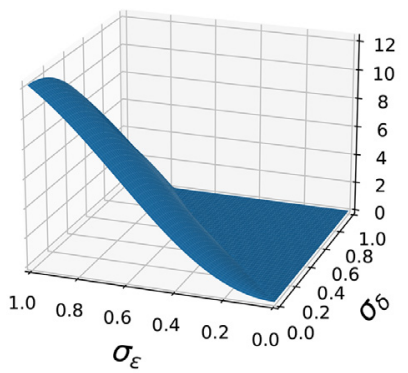

(a) Difference between late consumption with optimal policy and the first-best level of late consumption.

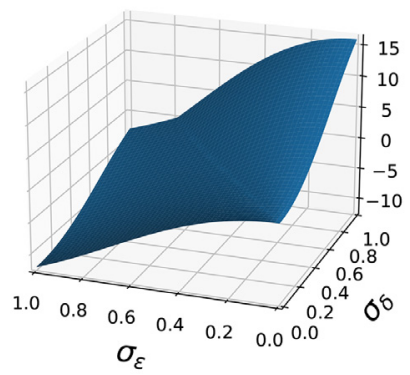

(b) Difference between late consumption at the optimal policy and the Friedman rule.

Fig. 10. Aggregate late consumption effects for log-normally distributed preferences shocks. All effects are expressed as a percentage of first-best late consumption.

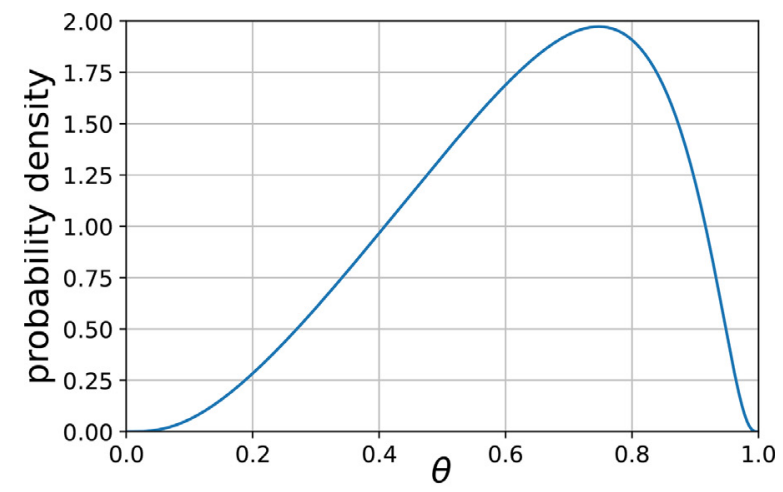

(a) $\operatorname{Pdf} \theta,\left\{\sigma_{\varepsilon}, \sigma_{\delta}\right\}=\{0.5,1\}$.

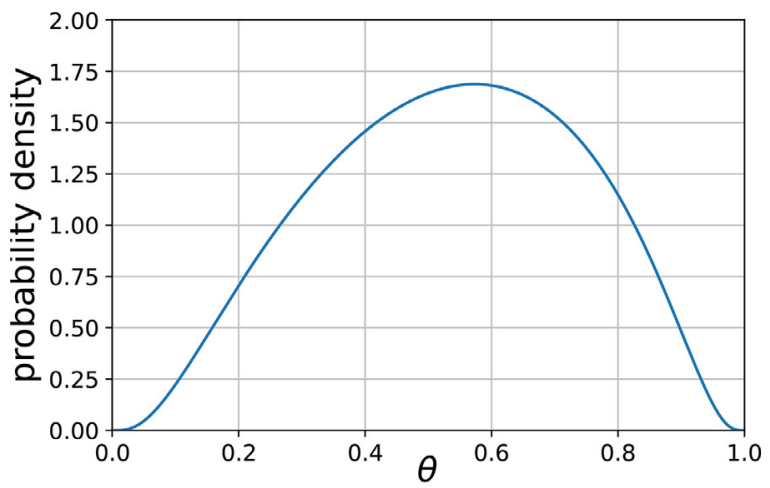

(b) $\operatorname{Pdf} \theta,\left\{\sigma_{\varepsilon}, \sigma_{\delta}\right\}=\{1,0.5\}$.

Fig. 11. Probability density function for $\theta$ with log-normally distributed preferences. 


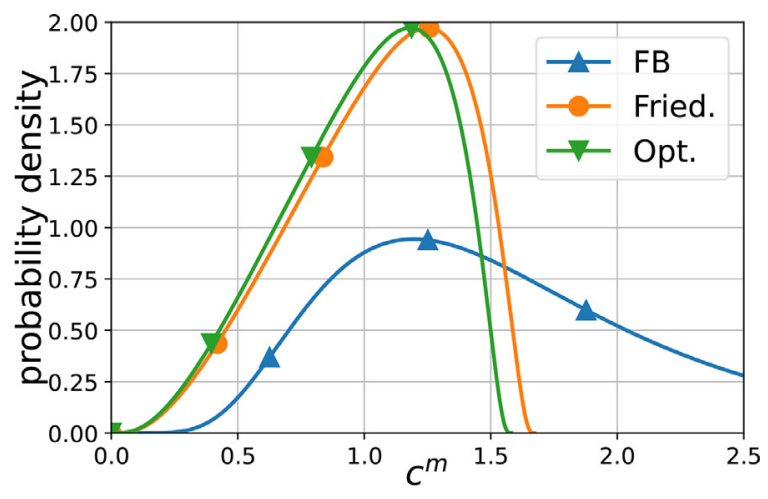

(a) Probability density function for early consumption.

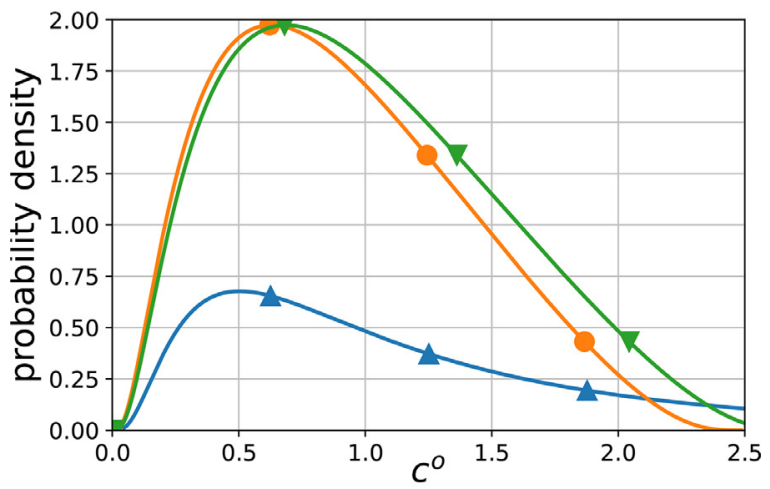

(b) Probability density function for late consumption.

Fig. 12. Consumption distribution for log-normally distributed preferences shocks with $\sigma_{\varepsilon}=0.5$ and $\sigma_{\delta}=1$. Optimal inflation in this case is $-1.68 \%$ and the optimal nominal rate is $1.0 \%$. The ZLB is slack. 


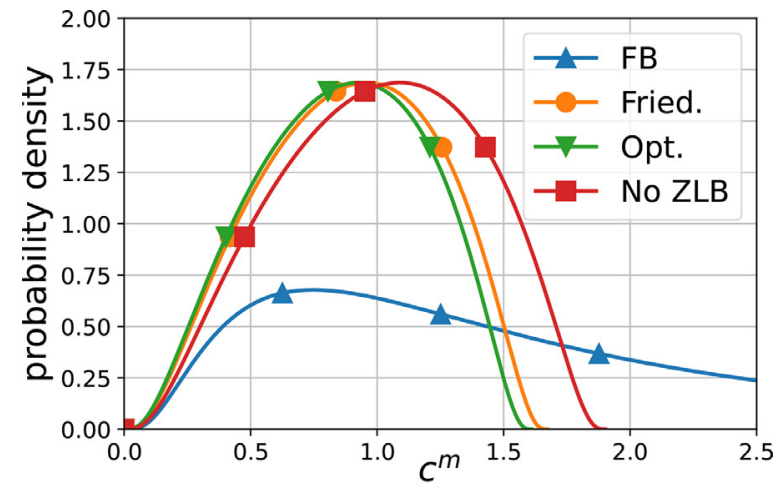

(a) Probability density function for early consumption.

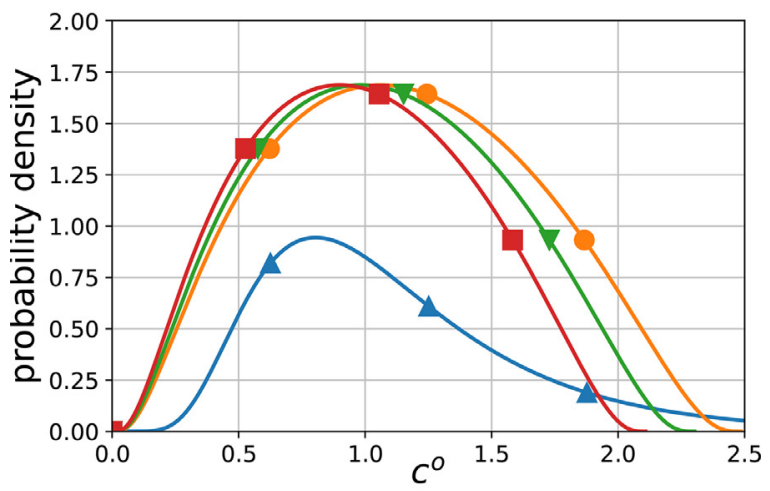

(b) Probability density function for late consumption.

Fig. 13. Consumption distribution for log-normally distributed preferences shocks with $\sigma_{\varepsilon}=1$ and $\sigma_{\delta}=0.5$. Optimal inflation in this case is $-1.77 \%$ and the optimal nominal rate is $0 \%$ as the ZLB binds. Absent a ZLB, optimal inflation would be $-2.59 \%$ and the optimal nominal rate $-2.1 \%$. 


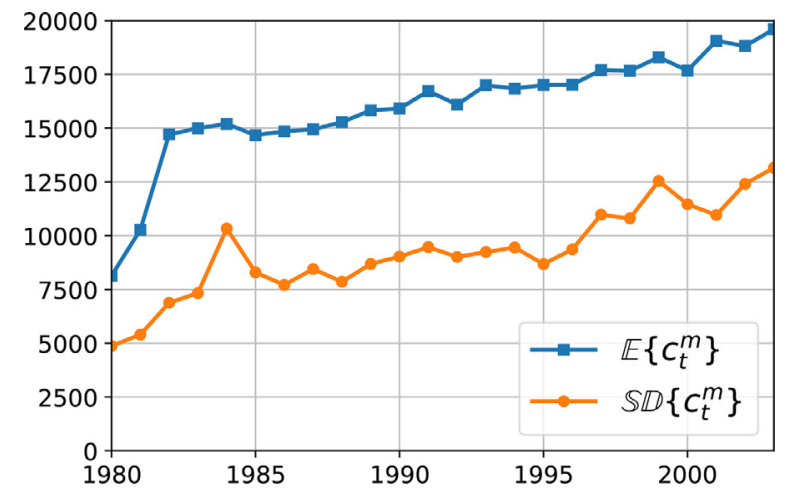

(a) Mean and standard deviation for middle-aged consumption.

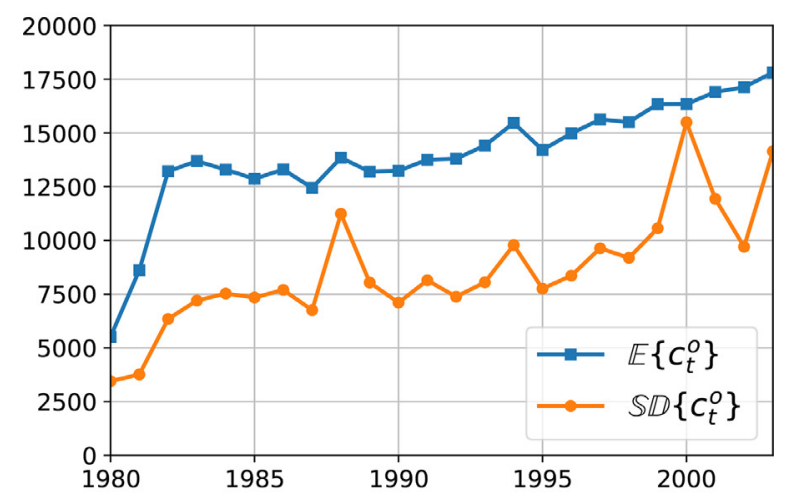

(b) Mean and standard deviation of old-aged consumption.

Fig. 14. Cross-sectional mean and standard deviations for core, non-durable consumption in our sample. Middle aged are all between the age of 45 up to and including 65. Old are all between the age of 65 and 75. Expenditures are expressed in year 2000 US Dollars and taken from the CEX data of Aguiar and Hurst (2013). 


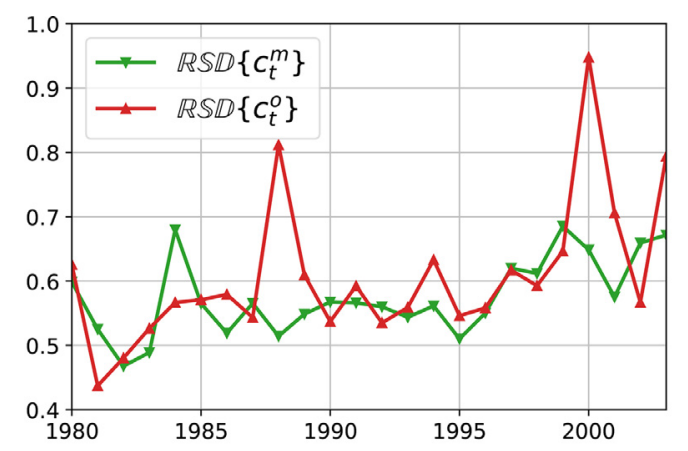

(a) Cross sectional relative standard deviations for middle- and old-aged consumption.

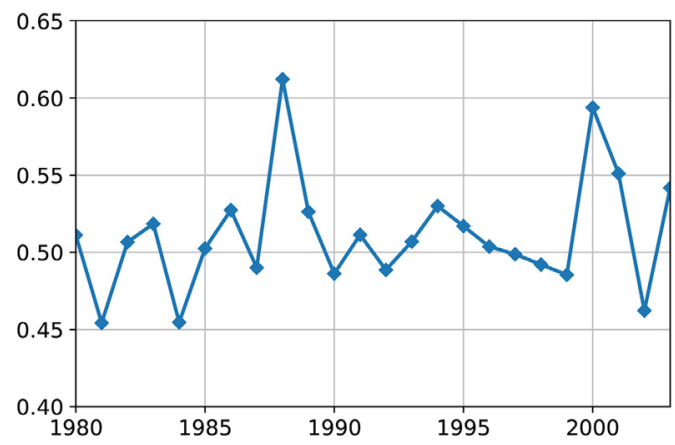

(b) The data-implied value of the sufficient statistic $\Theta$.

Fig. 15. Cross-sectional relative deviations for core, non-durable consumption in our sample. Middle aged are all between the age of 45 up to and including 65. Old are all between the age of 65 and 75. Expenditures are expressed in year 2000 US Dollars and taken from the CEX data of Aguiar and Hurst (2013). The sufficient statistic $\Theta$ is calculated from the formula $\Theta=\mathbb{R S D}\left\{q_{t}^{o}\right\} /\left[\mathbb{R S D}\left\{q_{t}^{m}\right\}+\mathbb{R S D}\left\{q_{t}^{o}\right\}\right]$. 


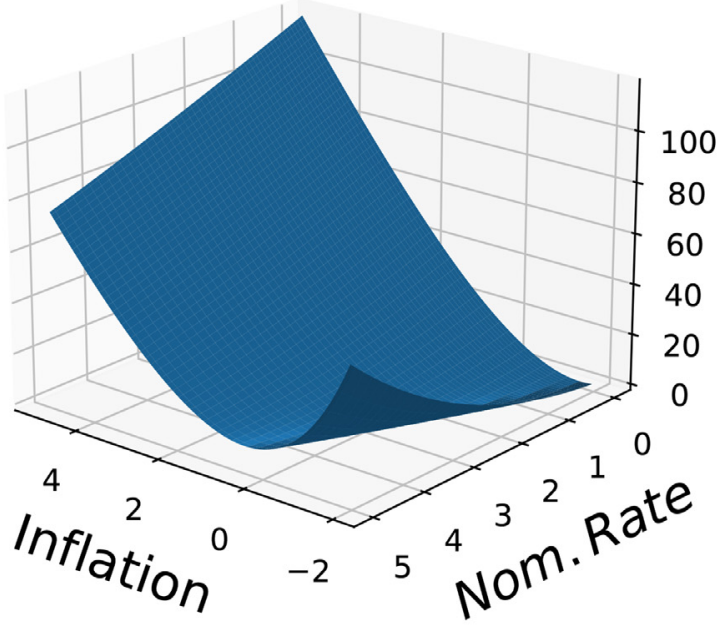

(a) Welfare loss relative to the optimal policy.

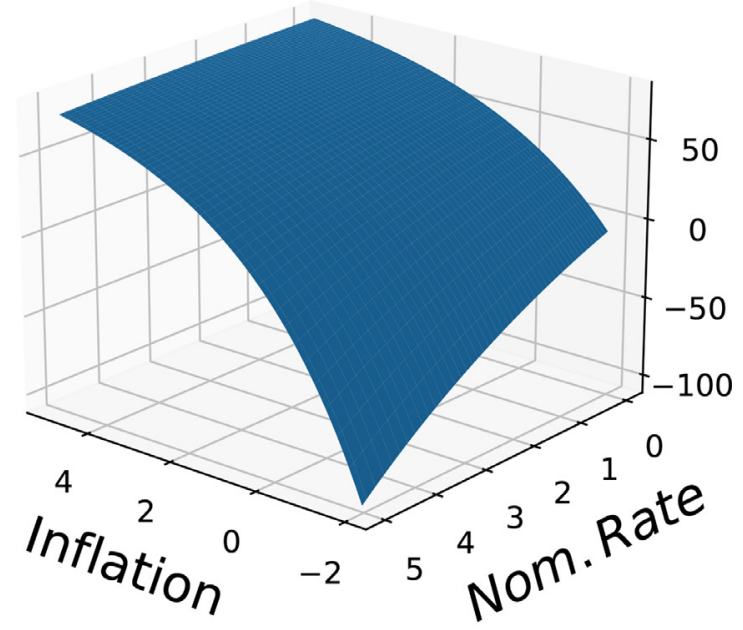

(b) Output loss relative to the optimal policy.

Fig. 16. Welfare and output losses (gains when negative) associated with deviating from the optimal policy. Losses (gains) are expressed as a percentage of first-best output. 


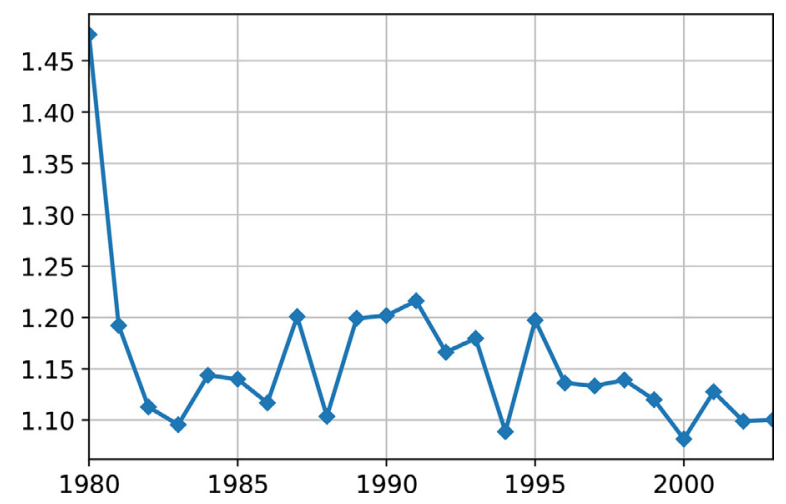

Fig. 17. The ratio of aggregate middle-aged consumption over aggregate old-aged consumption in the sample. Middle aged are all between the age of 45 up to and including 65. Old are all between the age of 65 and 75. Expenditures are expressed in year 2000 US Dollars and taken from the CEX data of Aguiar and Hurst (2013).

\section{Appendix B. Proofs and derivations}

B1. Derivations of real quantities in the benchmark model

We let $\beta \lambda_{\xi, t}$ denote the Lagrange multiplier associated with the (idiosyncratic) state-contingent budget constraint (3b). With log-utility, first-order conditions become:

$$
\begin{aligned}
& h_{t}: \quad 0=-1+\beta \mathbb{E}\left[\lambda_{\xi, t}\right], \\
& q_{\xi, t}^{m}: \quad 0=-\pi_{t+1} \lambda_{\xi, t}+\varepsilon / q_{\xi, t}^{m}, \\
& q_{\xi, t}^{o}: \quad 0=-\min \left\{\varphi_{t+1}\right\} \pi_{t+1} \pi_{t+2} \lambda_{\xi, t}+\beta \delta / q_{\xi, t}^{o} .
\end{aligned}
$$

Combining (B.2) and (B.3) results in

$$
q_{\xi, t}^{o}=q_{\xi, t}^{m} \frac{\beta \delta}{\varepsilon} \frac{1}{\min \left\{\varphi_{t+1}, 1\right\} \pi_{t+2}} .
$$

Using that the budget constraint (3b) must hold with equality, we find

$$
h_{t}=\pi_{t+1}\left[q_{\xi, t}^{m} \frac{\varepsilon+\beta \delta}{\varepsilon}+\tau_{t+1}\right] \text {. }
$$

Rewriting (B.5) in terms of $q_{\xi, t}^{m}$ and substituting into (B.2), we obtain

$$
\lambda_{\xi, t}=\frac{\varepsilon+\beta \delta}{h_{t}-\pi_{t+1} \tau_{t+1}} .
$$

Using this in (B.1) together with Assumption $1(\mathbb{E}[\varepsilon]=\mathbb{E}[\delta]=1)$ we find

$$
h_{t}=\beta(1+\beta)+\pi_{t+1} \tau_{t+1} .
$$

Using (B.7) in (B.5) yields an expression for $q_{\xi, t}^{m}$, which we can then use in (B.4) to obtain an expression for $q_{\xi, t}^{0}$ :

$$
q_{\xi, t}^{m}=\frac{\varepsilon}{\varepsilon+\beta \delta} \frac{\beta(1+\beta)}{\pi_{t+1}} \quad \text { and } \quad q_{\xi, t}^{o}=\frac{\beta \delta}{\varepsilon+\beta \delta} \frac{\beta(1+\beta)}{\min \left\{\varphi_{t+1}, 1\right\} \pi_{t+1} \pi_{t+2}} .
$$

\section{B2. Proof of Lemma 1}

When the ZLB does not bind, first-order conditions resulting from optimizing the welfare function at steady state with respect to $\pi$ (inflation rate) and $\varphi$ (bond prices) yields

$$
\pi^{*}=\Theta \beta(1+\beta)
$$

$$
\varphi^{*}\left(\pi^{*}\right)^{2}=\beta(1+\beta)(1-\Theta)
$$


Clearly, the ZLB binds if and only if $\varphi^{*}>1$. Using (B.9) and (B.10), this is the case when

$$
\Theta^{2}(1+\beta)^{2} \beta^{2}+\Theta \beta(1+\beta)-\beta(1+\beta)<0 .
$$

Condition (B.11) is satisfied for $-1 / \beta<\Theta<1 /(1+\beta)$. Because $\Theta \in(0,1)$, it follows that the ZLB binds if and only if $\Theta(1+$ $\beta)<1$.

\section{B3. Proof of Proposition 1}

There are two cases to consider: (i) binding ZLB (with $\varphi=1$ ) and (ii) non-binding ZLB (with $\varphi<1$ ). When $\varphi=1$, optimal $\pi$ is determined from:

$$
\begin{aligned}
& \pi=\frac{\beta(1+\beta) \Theta}{1-\chi(1+\beta)}, \\
& 1+\chi=\frac{\beta(1+\beta)}{\pi^{2}}(1-\Theta) .
\end{aligned}
$$

It follows that the optimal inflation rate $\pi$ can be solved as the unique positive root of the polynomial:

$$
\pi^{2}(2+\beta)-\pi \beta(1+\beta) \Theta-\beta(1+\beta)^{2}(1-\Theta)=0
$$

as stated in Proposition 1. In the case of non-binding ZLB with $\varphi<1$ (and thus $\chi=0$ ), the optimal inflation rate is determined as:

$$
\pi=\Theta \beta(1+\beta)
$$

which also yields:

$$
\varphi=\frac{1-\Theta}{\Theta^{2} \beta(1+\beta)} .
$$

\section{B4. Proof of Corollary 1}

That the optimal inflation rate satisfies $\pi \geq \beta$ for the case of $\Theta(1+\beta) \geq 1$ (with $\pi=\beta$ when $\Theta(1+\beta)=1$ ) follows immediately from the equation that pins down optimal policy mix in Proposition 1 . To observe that the optimal inflation is still greater than the Friedman rule, $\pi>\beta$, when $\Theta(1+\beta)<1$, we first note that at this particular case the equation that determines the optimal inflation satisfies

$$
(2+\beta) \pi^{2}-\Theta \beta(1+\beta) \pi-\beta(1+\beta)^{2}(1-\Theta)=0
$$

which has a unique positive root for $\pi$. Note that $\pi=\beta$ solves (B.17) if $\Theta(1+\beta)=1$. Then, starting at $\pi=\beta$ and $\Theta(1+$ $\beta$ ) $=1$, if $\Theta$ declines (such that $\Theta(1+\beta)<1$ ) the left-hand-side of (B.17) which solves for the optimal inflation with $\Theta(1+$ $\beta$ ) $<1$ goes down, since $\beta<1$. Also because at $\pi=\beta$ an increase in $\pi$ raises the left-hand-side of the polynomial, it yields the result that the optimal inflation rate satisfies $\pi>\beta$ for $\Theta(1+\beta)<1$.

\section{B5. Proof of Lemma 2}

Let $\beta \lambda_{\xi, t}, v_{h, t}$, and $v_{k, t}$ denote the Lagrange multipliers of the associated constraints. Because the non-negativity constraint for capital never binds due to the DRS technology specification, we obtain the following first-order conditions:

$$
\begin{aligned}
& h_{t}: \quad 0=-1+v_{h, t}+\beta \mathbb{E}\left[\lambda_{\xi, t}\right], \\
& k_{t}: \quad 0=-1+\varphi_{t+1} \pi_{t+1} \pi_{t+2} A k_{t}^{-\alpha} \beta \mathbb{E}\left[\lambda_{\xi, t}\right], \\
& q_{\xi, t}^{m}: \quad 0=\varepsilon / q_{\xi, t}^{m}-\pi_{t+1} \lambda_{\xi, t}, \\
& q_{\xi, t}^{o}: \quad 0=\delta \beta / q_{\xi, t}^{o}-\varphi_{t+1} \pi_{t+1} \pi_{t+2} \lambda_{\xi, t} .
\end{aligned}
$$

The solution clearly depends on whether the non-negativity constraint associated with young's labor supply, $h$, binds and thus whether there are intergenerational transfers in spirit of what we studied in Section 3. In what follows, we focus on equilibria that involve $h>0$. The amount of labor devoted to acquiring cash and investment goods is then given by

$$
h_{t}=\beta(1+\beta)+\pi_{t+1} \tau_{t+1}-\left[A \varphi_{t+1} \pi_{t+1} \pi_{t+2}\right]^{1 / \alpha} /(1-\alpha) \quad \text { and } \quad k_{t}=\left[A \varphi_{t+1} \pi_{t+1} \pi_{t+2}\right]^{1 / \alpha},
$$


respectively. When middle-aged, households' real financial wealth after taxation therefore equals $\beta(1+\beta) / \pi_{t+1}$. As in the benchmark model, early and late consumption are then given by (8) and aggregate supply of and demand for goods in any time period $t$ becomes:

$$
\begin{aligned}
& Q_{t}^{s}=\beta(1+\beta)+\pi_{t+1} \tau_{t+1}+A^{1 / \alpha}\left(\left[\varphi_{t-1} \pi_{t-1} \pi_{t}\right]^{\frac{1-\alpha}{\alpha}}-\left[\varphi_{t+1} \pi_{t+1} \pi_{t+2}\right]^{\frac{1}{\alpha}}\right) /(1-\alpha), \\
& Q_{t}^{d}=\Theta \beta(1+\beta) / \pi_{t}+\beta(1+\beta)(1-\Theta) /\left(\varphi_{t-1} \pi_{t-1} \pi_{t}\right) .
\end{aligned}
$$

The level of lump-sum taxes that closes the model and equilibriates demand and supply is given by:

$$
\begin{aligned}
\pi_{t} \tau_{t}= & \beta(1+\beta)\left\{\Theta\left[1 / \pi_{t-1}-1\right]+(1-\Theta)\left[1 /\left(\varphi_{t-2} \pi_{t-2} \pi_{t-1}\right)-1\right]\right\} \\
& -\frac{A^{1 / \alpha}\left(\left[\varphi_{t-2} \pi_{t-2} \pi_{t-1}\right]^{\frac{1-\alpha}{\alpha}}-\left[\varphi_{t} \pi_{t} \pi_{t+1}\right]^{\frac{1}{\alpha}}\right)}{1-\alpha} .
\end{aligned}
$$

It follows that total labor supply by young households satisfies:

$$
h_{t}+k_{t}=\frac{\Theta \beta(1+\beta)}{\pi_{t}}+\frac{\beta(1+\beta)(1-\Theta)}{\varphi_{t-1} \pi_{t-1} \pi_{t}}-A^{1 / \alpha}\left(\frac{\left[\varphi_{t-1} \pi_{t-1} \pi_{t}\right]^{\frac{1-\alpha}{\alpha}}}{1-\alpha}-\left[\varphi_{t+1} \pi_{t+1} \pi_{t+2}\right]^{\frac{1}{\alpha}}\right) .
$$

Focusing on a steady state, to ensure $h$ is strictly positive we need the following condition to hold in equilibrium:

$$
\frac{A^{\frac{1}{\alpha}}\left(\varphi \pi^{2}\right)^{\frac{1-\alpha}{\alpha}}}{1-\alpha}<\frac{\beta(1+\beta)(\varphi \pi \Theta+1-\Theta)}{\varphi \pi^{2}} .
$$

B6. Proof of Proposition 2

Let $\beta^{s+1-t} \chi_{s}$ denote the Lagrange multiplier on the ZLB constraint to obtain the following first order conditions

$$
\begin{aligned}
\pi_{s+2}: \quad 0=\beta^{2}\left(-\frac{2+\beta}{\pi_{s+2}}+\right. & \left.\frac{\Theta \beta(1+\beta)}{\pi_{s+2}^{2}}+\frac{\beta(1+\beta)(1-\Theta)}{\varphi_{s+1} \pi_{s+1} \pi_{s+2}^{2}}+\frac{\beta^{2}(1+\beta)(1-\Theta)}{\varphi_{s+2} \pi_{s+2}^{2} \pi_{s+3}}\right) \\
+ & \frac{\left[A \varphi_{s+1} \pi_{s+1} \pi_{s+2}\right]^{\frac{1}{x}}}{\alpha \pi_{s+2}}\left[\frac{\beta^{2}}{\varphi_{s+1} \pi_{s+1} \pi_{s+2}}-1\right] \\
+ & \beta \frac{\left[A \varphi_{s+2} \pi_{s+2} \pi_{s+3}\right]^{\frac{1}{\alpha}}}{\alpha \pi_{s+2}}\left[\frac{\beta^{2}}{\varphi_{s+2} \pi_{s+2} \pi_{s+3}}-1\right], \\
\varphi_{s+1}: \quad 0= & \beta^{2}\left(-\chi_{s+1}-\frac{1}{\varphi_{s+1}}+\frac{\beta(1+\beta)(1-\Theta)}{\varphi_{s+1}^{2} \pi_{s+1} \pi_{s+2}}\right) \\
& +\frac{\left[A \varphi_{s+1} \pi_{s+1} \pi_{s+2}\right]^{\frac{1}{\alpha}}}{\alpha \varphi_{s+1}}\left[\frac{\beta^{2}}{\varphi_{s+1} \pi_{s+1} \pi_{s+2}}-1\right] .
\end{aligned}
$$

Focusing on steady state, the first-order conditions reduce to:

$$
\pi=\Theta \beta(1+\beta)+\chi \pi(1+\beta) \text { and } \varphi \pi^{2}=\beta(1+\beta)(1-\Theta)-\chi \varphi \pi^{2}+\left[A \varphi \pi^{2}\right]^{\frac{1}{\alpha}}\left[1-\varphi \pi^{2} / \beta^{2}\right] / \alpha .
$$

We note that in steady state, the investment technology enters only in the first-order condition for $\varphi$. However, through the Lagrange multiplier for the ZLB, inflation can be affected by the investment technology.

Then, we show that the ZLB binds if and only if $\Theta(1+\beta)<1$. Consider first $\Theta(1+\beta) \geq 1$ and conjecture that the ZLB is slack this case. Then Eq. (B.30) implies

$$
\pi \geq \beta \text { and } \varphi \pi^{2} \leq \beta^{2}+\left[A \varphi \pi^{2}\right]^{\frac{1}{\alpha}}\left[1-\varphi \pi^{2} / \beta^{2}\right] / \alpha \Rightarrow \varphi \pi^{2} \leq \beta^{2} .
$$

It follows that $\varphi \leq 1$, which verifies our conjecture. Consider second that $\Theta(1+\beta)<1$ and suppose that the ZLB is also slack in this case. Then Eq. (B.30) implies

$$
\pi<\beta \text { and } \varphi \pi^{2}>\beta^{2}+\left[A \varphi \pi^{2}\right]^{\frac{1}{\alpha}}\left[1-\varphi \pi^{2} / \beta^{2}\right] / \alpha \Rightarrow \varphi \pi^{2}>\beta^{2}
$$

It follows that $\varphi>1$, which yields a contradiction. Hence the ZLB must bind when $\Theta(1+\beta)<1$.

Next, we characterize optimal policy with a slack ZLB constraint. Clearly

$$
\pi=\Theta \beta(1+\beta) \text { and } \varphi \pi^{2}=\beta(1+\beta)(1-\Theta)+\left[A \varphi \pi^{2}\right]^{\frac{1}{\alpha}}\left[1-\varphi \pi^{2} / \beta^{2}\right] / \alpha
$$

Letting $\varphi \pi^{2}=\beta(1+\beta)(1-\Theta)+o_{\varphi}^{\prime}$ we have that

$$
o_{\varphi}^{\prime}=\frac{A^{1 / \alpha}\left[\beta(1+\beta)(1-\Theta)+o_{\varphi}^{\prime}\right]^{1 / \alpha}}{\alpha}\left[1-\frac{\beta(1+\beta)(1-\Theta)+o_{\varphi}^{\prime}}{\beta^{2}}\right] .
$$


With $\Theta(1+\beta) \geq 1$, this implies that $o_{\varphi}^{\prime} \geq 0$ with strict inequality if $A>0$, as well as $\lim _{A \rightarrow 0} o_{\varphi}^{\prime}=0$. When $A$ is sufficiently small, Eq. (B.34) also pins down $o_{\varphi}^{\prime}$ uniquely. Then, $\partial o_{\varphi}^{\prime} / \partial A>0$. Finally,

$$
\varphi=\frac{1-\Theta}{\Theta \beta(1+\beta)}+o_{\varphi} \text { and } o_{\varphi}=\frac{o_{\varphi}^{\prime}}{[\Theta \beta(1+\beta)]^{2}},
$$

where $o_{\varphi}$ has the same qualitative properties as $o_{\varphi}^{\prime}$.

Finally, we characterize optimal policy with a tight ZLB constraint. Using $\varphi=1$, Eq. (B.30) implies that

$$
0=(2+\beta) \pi^{2}-\Theta \beta(1+\beta) \pi-\beta(1+\beta)^{2}(1-\Theta)-\left[A \pi^{2}\right]^{1 / \alpha}\left[1-\pi^{2} / \beta\right](1+\beta) / \alpha .
$$

With $\Theta(1+\beta)<1$, the RHS of Eq. (B.36) is negative for all $\pi \leq \beta$. The partial derivative of the RHS of Eq. (B.36) w.r.t. $\pi$ satisfies

$$
2 \pi(2+\beta)-\Theta \beta(1+\beta)-2 \pi\left[A \pi^{2}\right]^{1 / \alpha}\left[\frac{1}{\alpha}\left(\frac{1}{\pi^{2}}-\frac{1}{\beta}\right)-\frac{1}{\beta}\right] \frac{1+\beta}{\alpha},
$$

which is strictly positive for $\pi>\beta$. Therefore, there exists a unique $\pi>\beta$ which solves Eq. (B.36) and which constitutes the optimal rate of inflation. Clearly, this solution is decreasing in $A$ and can be written as

$$
\pi=\Upsilon-o_{\pi} \quad \text { and } \quad \Upsilon=(1+\beta) \frac{\theta \beta+\sqrt{\beta} \sqrt{\beta \Theta^{2}+4(2+\beta)(1-\Theta)}}{2(2+\beta)},
$$

with $o_{\pi}=0$ if $A=0, o_{\pi}>0$ if $A>0, \partial o_{\pi} / \partial A>0$, and $\lim _{A \rightarrow 0} o_{\pi}=0$. Here $o_{\pi}$ is the unique positive solution to:

$$
0=o_{\pi}\left[o_{\pi}(2+\beta)-2 \mathrm{Y}(2+\beta)+\Theta \beta(1+\beta)\right]-\left[A\left(\mathrm{Y}-o_{\pi}\right)^{2}\right]^{\frac{1}{\alpha}}\left[1-\left(\mathrm{Y}-o_{\pi}\right)^{2} / \beta^{2}\right](1+\beta) / \alpha
$$

\section{References}

Aguiar, M., Hurst, E., 2013. Deconstructing life cycle expenditure. J. Polit. Economy 121 (3), 437-492.

Andolfatto, D., 2011. A note on the societal benefits of illiquid bonds. Can. J. Econ. 44 (1), 133-147.

Auernheimer, L., 1974. The honest government's guide to the revenue from the creation of money. J. Polit. Economy 82 (3), $598-606$.

Bencivenga, V.R., Smith, B.D., 1991. Financial intermediation and endogenous growth. Rev. Econ. Stud. 58 (2), $195-209$.

Berentsen, A., Camera, G., Waller, C.J., 2005. The distribution of money balances and the nonneutrality of money. Int. Econ. Rev. 46 (2), $465-487$.

Bhattacharya, J., Haslag, J.H., Martin, A., 2005. Heterogeneity, redistribution, and the Friedman rule. Int. Econ. Rev. 46 (2), $437-454$.

Bhattacharya, S., Padilla, A.J., 1996. Dynamic banking: a reconsideration. Rev. Financ. Stud. 9 (3), $1003-1032$.

Boel, P., Camera, G., 2006. Efficient monetary allocations and the illiquidity of bonds. J. Monet. Econ. 53 (7), 1693-1715. doi:10.1016/j.jmoneco.2006.02.002.

Boel, P., Waller, C.J., 2019. Stabilization policy at the zero lower bound. Int. Econ. Rev. 60 (4), 1539-1563. doi:10.1111/iere.12396.

Cagetti, M., 2003. Wealth accumulation over the life cycle and precautionary savings. J. Bus. Econ. Stat. 21 (3), $339-353$.

Curran, M.P., Dressler, S.J., 2019. Preference Heterogeneity, Inflation, and Welfare. Villanova School of Business Department of Economics and Statistics Working Paper Series 40. Villanova School of Business Department of Economics and Statistics.

De Nardi, M., Fella, G., 2017. Saving and wealth inequality. Rev. Econ. Dyn. 26, 280-300. doi:10.1016/j.red.2017.06.002.

Deaton, A., Paxson, C., 1994. Intertemporal choice and inequality. J. Polit. Economy 102 (3), 437-467.

Diamond, D.W., Dybvig, P.H., 1983. Bank runs, deposit insurance, and liquidity. J. Polit. Economy 91 (3), $401-419$.

Dong, F., Wen, Y., 2017. Optimal Monetary Policy under Negative Interest Rate. Working Papers 2017-19. Federal Reserve Bank of St. Louis doi:10.20955/wp. 2017.019.

Gârleanu, N., Panageas, S., 2015. Young, old, conservative, and bold: the implications of heterogeneity and finite lives for asset pricing. J. Polit. Economy 123 (3), 670-685.

Gelman, M., 2021. What drives heterogeneity in the marginal propensity to consume? Temporary shocks vs persistent characteristics. J. Monet. Econ. 117, 521-542. doi:10.1016/j.jmoneco.2020.03.006.

Golosov, M., Troshkin, M., Tsyvinski, A., Weinzierl, M., 2013. Preference heterogeneity and optimal capital income taxation. J. Public Econ. 97, 160-175. doi:10.1016/j.jpubeco.2012.10.006.

Gomis-Porqueras, P., Waller, C.J., 2017. Optimal Taxes Under Private Information: The Role of the Inflation. Working Papers 2017-014. Federal Reserve Bank of St. Louis doi:10.20955/wp.2017.014.

Hendricks, L., 2007. How important is discount rate heterogeneity for wealth inequality? J. Econ. Dyn. Control 31 (9), $3042-3068$. doi:10.1016/j.jedc.2006. 10.002 .

Hiraguchi, R., 2017. Optimal monetary policy in an overlapping generations model with search theoretic monetary exchange:. B.E. J. Theor. Econ. 17 (2), 20160039. doi:10.1515/bejte-2016-0039.

Kocherlakota, N.R., 2003. Societal benefits of illiquid bonds. J. Econ. Theory 108 (2), 179-193. doi:10.1016/S0022-0531(03)00029-2.

Krusell, P., Smith, A.A., 1998. Income and wealth heterogeneity in the macroeconomy. J. Polit. Economy 106 (5), $867-896$.

Lagos, R., Wright, R., 2005. A unified framework for monetary theory and policy analysis. J. Polit. Economy 113 (3), $463-484$.

Martin, A., Skeie, D., von Thadden, E.-L., 2014. The fragility of short-term secured funding markets. J. Econ. Theory 149, 15-42. doi:10.1016/j.jet.2013.10.006. (Financial Economics).

Martin, A., Skeie, D., von Thadden, E.-L., 2014. Repo runs. Rev. Financ. Stud. 27 (4), 957-989.

Qi, J., 1994. Bank liquidity and stability in an overlapping generations model. Rev. Financ. Stud. 7 (2), $389-417$.

Van Buggenum, H., 2021. Coexistence of Money and Interest-Bearing Bonds. CentER Discussion Paper 2021-019. Tilburg University, Center for Economic Research.

Venti, S.F., Wise, D.A., 2000. Choice, Chance, and Wealth Dispersion at Retirement. NBER Working Papers 7521. National Bureau of Economic Research, Inc. Williamson, S.D., 2019. Low real interest rates and the zero lower bound. Rev. Econ. Dyn. 31, 36-62. doi:10.1016/j.red.2018.12.003.

Zhu, T., 2008. An overlapping-generations model with search. J. Econ. Theory 142 (1), 318-331. doi:10.1016/j.jet.2007.01.020. 